\title{
CRACKING THE CODE
}

Influencing Millennial Science Engagement

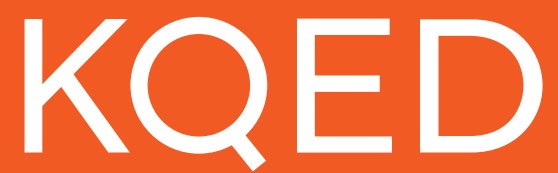

PRELIMINARY REPORT \#2 I DIGITAL VIDEO

A Deep look at the

Beneffits of Behind-

the-Scenes Content A Scientific Investigation into Seeing the Producers of KQED's Nature Series at Work

\section{REPORT AUTHORS}

Othello Richards and Asheley R. Landrum Texas Tech University November 2, 2020

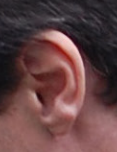

FUNDING

National Science Foundation DRL-1810990

\section{IN PARTNERSHIP WITH}




\section{NOTE}

This report describes the results of an ongoing research program aimed at promoting science-informed reporting of science media, news and insights. Project sponsors include the National Science Foundation, the John Templeton Foundation, and the Annenberg Public Policy Center at the University of Pennsylvania. The report was prepared for internal use by the project team members, who include both professional science communicators affiliated with KQED, a public media outlet located in San Francisco, California; and empirical researchers affiliated with Texas Tech University College of Media \& Communication. The report is being publicly disseminated not only to share knowledge generated by the team's initial research but also to improve comprehension of how collaborative exchange between researchers and practitioners can promote genuine evidence-based methods of science communication.

The research team members who conducted the study featured in this report include:

Josh Cassidy, KQED

Sevda Eris, KQED

Jasmine Garnett, KQED*

Alex Irwin, KQED

Aine Henderson, KQED

Kristina Janét, Texas Tech University

Asheley Landrum, Texas Tech University

Sue Ellen McCann, KQED

Sarah Mohamad, KQED

Jenny Oh, KQED

Gabriela Quirós, KQED

Othello Richards, Texas Tech University*

Paul Rogers, KQED*

Craig Rosa, KQED

Mike Seely, KQED

Lauren Sommer, KQED*

FOR MORE INFORMATION, please visit the KQED's Cracking the Code web page KQED.org/CrackingtheCode. We also welcome inquiries from researchers, science filmmakers and related science-communication professionals, and other curious and reflective people. For specific inquiries about this behind-the-scenes report, please contact Asheley Landrum at a.landrum@ttu.edu and/or Sevda Eris at seris@kqed.org. For general Cracking the Code inquiries please contact Sue Ellen McCann at smccann@kqed.org.

SUGGESTED CITATION: Richards, O. \& Landrum, A. R. (2020, October 28). A Deep Look at the Benefits of Behind-the-Scenes Content: A Scientific Investigation into Seeing the Producers of KQED's Nature Series at Work. (Preliminary Report \#2). San Francisco, CA: KQED.org https://www.kqed.org/about/15515/cracking-the-code-deeplook-behind-the-scenes

* Jasmine Garnett departed KQED in September 2020 and is now at SFGate.

Othello Richards departed Texas Tech University in July 2020 and is now at Brigham Young University.

Paul Rogers departed KQED in August 2020 and is now at the San Jose Mercury News.

Lauren Sommer departed KQED in January 2020 and is now at National Public Radio. 


\section{TABLE OF CONTENTS}

A. Overview and summary conclusions ……

B. Study background and motivations

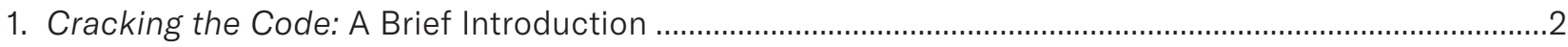

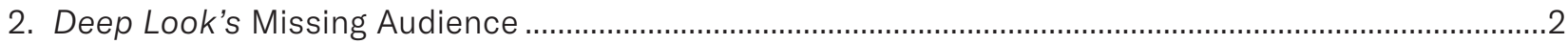

3. Current Issues with Behind-the-Scenes Content................................................................................ 3

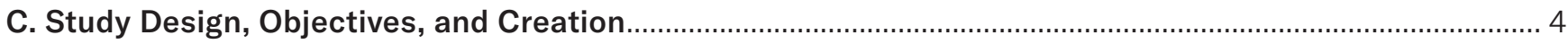

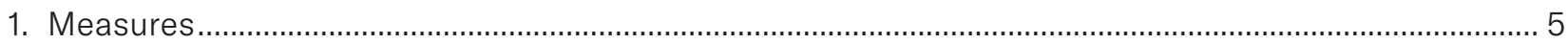

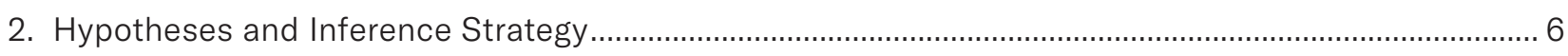

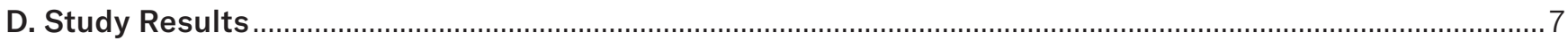

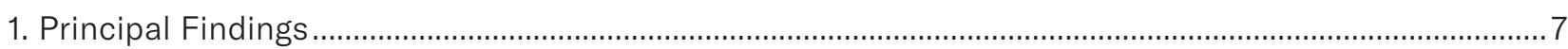

a. There does not appear to be any measurable benefits to attaching the produced behind-the-scenes episodes to the original episodes................................................................... 7

b. The BTS slideshow may be a more resource-efficient way to increase engagement and

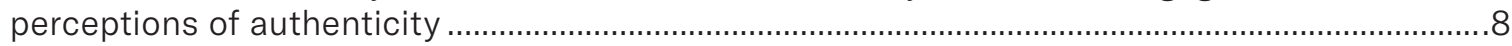

c. Unproduced BTS videos may have negative consequences for women who are science open..8

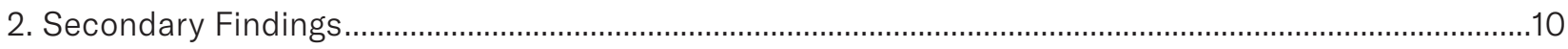

a. Science curiosity is a strong predictor of each of the outcome variables. ....................................10

b. There is a gender difference in science curiosity .........................................................................11

c. Millennials and Generation X are more science curious than Baby Boomers .............................. 12

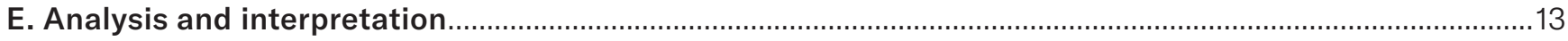

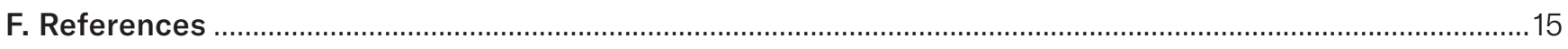

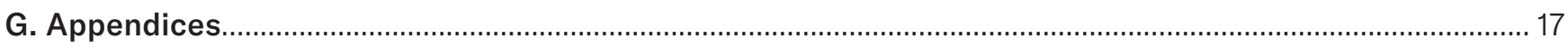

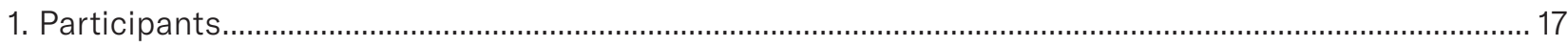

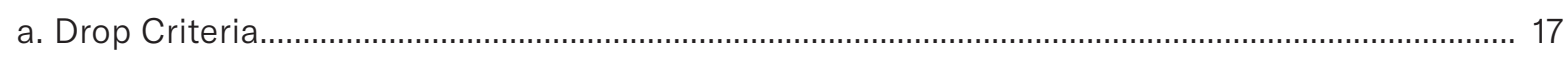

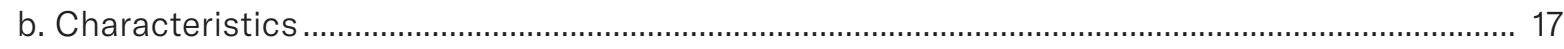

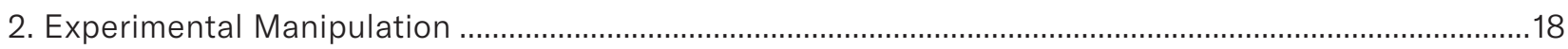

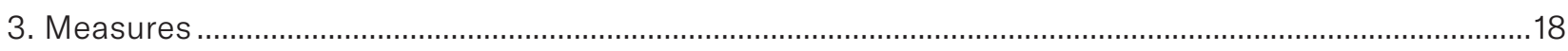

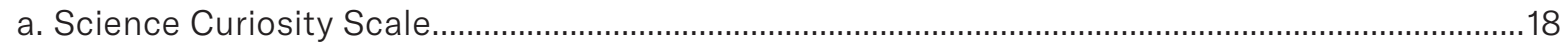

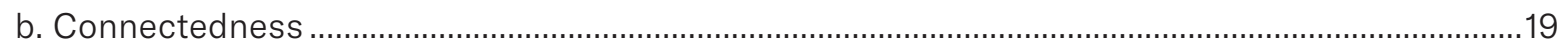

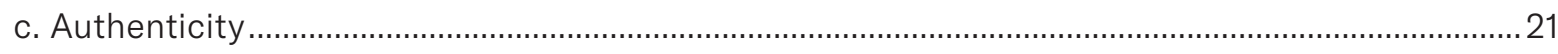

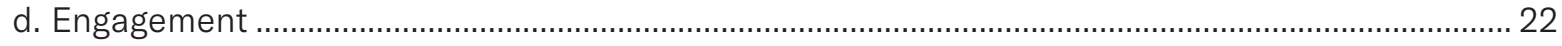

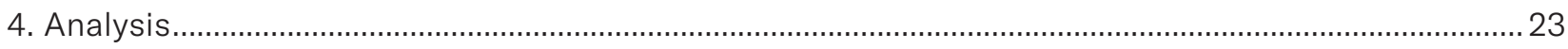




\section{TABLE OF FIGURES}

Figure 1. Screenshot from the survey

Figure 2. Four audiences based on science curiosity score quartiles: uninterested (bottom 25\%), indifferent (25th to 50 th percentile), open (50th to 75 th percentile), curious (top 25\%).

Figure 3. Visualization of the interaction between type of BTS content, science curiosity, and gender, when predicting participants' feelings of connectedness with the series narrator and the production crew members.

Figure 4. Visualization of the three-way interaction effect between type of BTS content, science curiosity, and gender, when predicting participants' perceptions of authenticity

Figure 5. Visualization of the three-way interaction between type of BTS content, science curiosity, and gender on participants' engagement.

Figure 6. Science curiosity score strongly predicts each of the outcome variables in each of the conditions. LOESS curves are shown 10

Figure 7. Distribution of science curiosity scores for males and females. Males are 1.67 times more likely to score in the top quarter (science curious audience) than females. Scores to the right of the orange dashed line are in the top $25 \%$ of SCS scores.

Figure 8. Distribution of science curiosity scores for Baby Boomers, Generation X and Millennials. Compared to Baby Boomers, Millennials are 2.9 times more likely (and GenX is 2.8 times more likely) to score in the top quarter of science curiosity scores. Scores to the right of the orange dashed lie are in the top $25 \%$ of SCS scores.

Figure 9. Distribution of science curiosity scores for this study sample 19

Figure 10. Distribution of connectedness scores for this study sample........ 20

Figure 11. Distribution of authenticity scores for this study sample.

Figure 12. Distribution of engagement scores for this study sample 22

Figure 13. Conceptual (left) and statistical (right) diagrams 23 


\section{REPORT}

\section{A. Overview and summary conclusions}

KQED's Deep Look team has produced a handful of behind-the-scenes (BTS) videos in order to: 1) introduce fans to the production team;2) deepen audience connection to the series, which does not feature an on-screen host and is not personality driven; and 3) help answer fans' questions about production methods. Despite the potential benefits of delivering BTS content, there are also several drawbacks. For example, creating the existing BTS episodes required sending out an additional crew to film the Deep Look crew filming the episode.

Two fundamental questions inspired the current study:

1. Are there enough benefits from the BTS episodes to justify production costs?

2. Is there a more resource-efficient way to gain benefits from BTS content?

To this end, we investigated whether the inclusion of different types of BTS content attached to the end of an episode influenced three potential benefits: increasing viewers' feelings of connectedness with the series and its narrator and producers; increasing viewers' perceptions of Deep Look's authenticity; and increasing viewers' engagement with the program.

In the study, participants were randomly assigned to watch a Deep Look episode with BTS content attached. We used several varieties of BTS content with varying degrees of production quality and cost: a fully produced BTS video (i.e., "produced video"), video outtakes (i.e., "unproduced video"), and a photo slideshow (i.e., "BTS Photos" or "pictures"). See Glossary.

We also had two control conditions that did not feature BTS content: (1) the original episode with no added content (i.e., "the original") and (2) the original episode with an added on-camera appearance of the series' narrator at the opening of the episode (i.e., "the stand-up"). This second control condition was used to examine whether simply seeing someone on camera increased viewers' feelings of connectedness and perceptions of authenticity separate from the content being "behind the scenes."

\section{Glossary}

\section{TERM/CONDITION}

STIMULUS LINK

Semi-unpolished content that shows followers what happens behind the brand, including the culture, management, and everyday workings of the business. Social media and branding experts state that promoting behind-the-scenes content on social media helps cultivate personal connection with consumers, create brand authenticity, and increase engagement (Daniels, 2014; O’Brien, 2018; Vidwheel, 2019).

The level of intensity of the relationship that viewers develop with a program and its characters. We measured connectedness using a 10-item, modified version of the connectedness scale (Russel et al., 2004).

Connectedness The perceived reality and truthfulness of a brand. We measured authenticity using an 8-item, modified brand authenticity scale (Napoli et al., 2014).

To measure engagement, we combined a number of subjective and behavioral indicators,

Authenticity such as asking participants if they wanted to share the video on social media and what

Engagement comments or questions they had about the content.

The original Deep Look episode that is uploaded on YouTube. These include two episodes

Original Episode titled, "Decorator Crabs Make High Fashion at Low Tide" and "A Sand Dollar's Breakfast is Totally Metal."

Produced BTS

Professionally shot and edited behind-the-scenes video package that is narrated and includes interviews of production team members.

Raw video footage or outtakes of the production team (e.g., watching the videographer film

Unproduced BTS sand dollars underwater; a snippet of a conversation between Deep Look team members and a biologist).

BTS Photos

Photos taken of the production team on location. Several photos are edited together into a short (10 to 15 seconds) slideshow.

The series' host introduces the content of the original episode. A stand-up runs

Stand-up w/ Host
Decorator Crab

$\underline{\text { Sand Dollar }}$

Decorator Crab Sand Dollar

Decorator Crab

Sand Dollar

Decorator Crab Sand Dollar Decorator Crab Sand Dollar 
Furthermore, we examined how users' science curiosity (i.e., their natural inclination to consume science-related media for personal satisfaction, Kahan et al., 2017) influenced their feelings of connectedness, perceptions of authenticity, and engagement. And, given results from our prior study that suggests that science-curious women are an important missing audience for Deep Look (Kahan, 2019), we examined the extent to which participants' responses varied by gender.

Major findings of this study include:

1. The measurable benefits of appending a fully produced behind-the-scenes video to a Deep Look episode appear to exist primarily among individuals outside Deep Look's target audience (science-curious individuals). Women low in science curiosity who watched the produced BTS content rated Deep Look as more authentic and demonstrated greater engagement than women of similar science curiosity who only watched the original episode. On the other hand, men low in science curiosity who watched the original episode perceived Deep Look as more authentic than watching the episode with the appended produced BTS video. There was no difference in feelings of connectedness, perceptions of authenticity, or engagement among individuals with high science curiosity.

2. A short behind-the-scenes slideshow may be a resource-efficient way of increasing engagement not only among Deep Look's traditional audience (highly science-curious men), but also among two very different audiences-women who are science curious and those who are not. Highly science-curious men who watched the Deep Look episode with the appended BTS slideshow reported greater perceived authenticity than men of similar science curiosity who viewed only the original episode. Highly science-curious women were greatly engaged in both conditions. Women indifferent to science who were in the BTS slideshow condition, too, were more engaged than similar women who saw only the original episode.

3. Appending unproduced BTS content (i.e., raw BTS video) to a Deep Look episode does not score as high among science-curious women compared to viewing just the original episode. Women high in science curiosity perceived the episode with the attached unproduced BTS video as less authentic and demonstrated lower engagement than similar science-curious women who viewed only the standalone Deep Look episode.

4. Compared to those who are less science-curious, overall, people who are more science curious report feeling more connected with the series, report perceiving the series to be more authentic, and demonstrate greater engagement with the content.

\section{B. Study background and motivations}

\section{Cracking the Code: A Brief Introduction}

This report details findings in the ongoing National Science Foundation-funded project, Cracking the Code: Influencing Millennial Science Engagement. Spearheaded by science media professionals and "science of science communication" researchers, one of the project aims is to develop best practices for engaging young adults with science media (Eris, 2019). More specifically, this work seeks to identify and target public science media's missing audiences.

The so-called "missing audience" for science media consists of individuals that should, by all accounts, be interested in engaging with this type of content (e.g., are science curious), but for an unknown reason are not. Data from our first survey suggests that millennials account for roughly onethird of the missing audience, depending on the platform, and women are disproportionately high in this identification (Eris, 2019; Kahan, 2019).

\section{Deep Look's Missing Audience}

Indeed, San Francisco-based public media outlet KQED has witnessed gender disparity in the viewership of its Deep Look online series. Deep Look provides users with an ultra-high-definition and up-close look at a variety of nature's creatures (e.g., ants, sand dollars, bed bugs), some on the nearmicroscopic level. Metrics from YouTube suggest that a large proportion of Deep Look's audience is male, approximately $70 \%$. Some individual episodes can skew as high as $90 \%$ male viewership. Results from the study "A Deep Look at Gender Disparity" suggest that this imbalance might exist because sciencecurious women who have modest levels of science comprehension are less likely to choose to watch certain Deep Look episodes than men with similar 
science interests and understandings (Kahan, 2019). Notably, the study found no divergence in engagement $^{1}$ among those men and women who did choose to watch.

Although the study described in this report does not directly examine the Deep Look gender disparity, it does examine gender differences in response to Deep Look's behind-the-scenes content.

\section{Current Issues with Behind-the-Scenes Content}

The producers of Deep Look have created professionally produced and edited behind-thescenes (i.e., BTS) videos for only a handful of episodes out of the more than one hundredepisodes in the series. These short BTS videos provide audiences with an inside look at what goes into capturing the spectacular footage that the content creators piece together into episodes.

The purpose of BTS footage is to provide more opportunities for Deep Look fans to engage, but that opportunity comes at a cost. Producing the BTS episodes requires additional staff and production work hours, and these two factors are a rare luxury for any public media outlet. In addition, posting BTS videos on the Deep Look series channel can have unintended negative consequences. Deep Look senior digital editor Craig Rosa explains:

If a channel puts out a video that performs poorly, then the next video from that channel will get less priority, and fewer opportunities to get viewed (at least initially). BTS videos in our experience have gotten way, way less traffic than our regular episodes, presumably because only a subset of our followers - likely our most ardent fans - will find them interesting.

So, when we put out a BTS video that gets $70 \mathrm{~K}$ views, instead of our usual 700K+, then we get dinged because the YouTube algorithm presumes we've made a crummy episode and are not serving our audience well. That's not helpful to us, because for our purposes it's of great value to provide BTS content to our biggest fans. But the algorithm does not care because it seeks as many happy eyeballs as possible to stay on the site for ads and other services. In short, YouTube's business goals do not always line up with our editorial and engagement objectives.

To get around the described issues, the Deep Look producers have posted their BTS videos as "unlisted" on their YouTube channel. Although unlisted videos can be shared, being unlisted makes these videos available only when linked to or embedded directly; consequently, they live outside of most of the typical discovery mechanisms on YouTube and are even less likely to be viewed organically.

As Rosa stated, the few BTS videos that have been posted to the Deep Look YouTube channel have not garnered a considerable number of views, because behind-the-scenes videos were only embedded in KQED's blog posts about Deep Look's behind-the-scenes work and promoted through social platforms such as Facebook and Twitter. At the time, YouTube did not have a community tab feature for channels to post BTS videos. For example, an episode on Caddisflies posted in 2016 currently has 2.8 million views, whereas its standalone BTS video only has a little more than 100,000 views.

So, why produce behind-the-scenes content at all?

One potential benefit of producing BTS content is that such content may increase viewers' feelings of connectedness and their engagement with Deep Look as well as viewers' perceptions of the brand's authenticity.

\footnotetext{
Watching BTS content might increase how connected users feel with the series and its narrator and producers. Academic researchers have defined connectedness as the level of intensity of the relationship that viewers develop with a program and its characters (Russel, Norman, \& Heckler, 2004). Viewers who feel connected to a program tend to frequent related websites, post on message boards and Facebook, and buy products featured on the show (Patino, Kaltcheva, \& Smith, 2011), all of which are indicators of greater engagement.
}

Engagement was measured using a scale that combined items including those that ask participants to write down questions and comments they had about the Deep Look episode that they viewed, whether they wanted to share the video, and if they would like to subscribe to updates about the series via emails and social media, among other engagement indicators. Because we used an index, it is possible that levels of engagement may be the same though the modes of engagement may vary. 
Producing behind-the-scenes content provides opportunities to showcase the team behind a project and educate audiences on the extent of the work involved in completing the production (Lush Content, 2020). According to Phoenix-based video production company Point in Time Studios, BTS content also humanizes a company and allows viewers to connect with their audience more fully ("Why you need," 2018). In the academic literature, this type of intimate connection is referred to as parasocial interaction (PSI), a one-way friendship, or sense of intimacy a viewer develops with a media personality (Dibble, Hartmann, \& Rosaen, 2016; Rubin, Perse, \& Powell, 1985). Scholars have argued that parasocial interaction can sometimes be a more important motivation to watch than the content of the program itself (Giles, 2002, p. 282).

Watching BTS content might increase viewers' perceptions of the brand's authenticity. Scholars have commonly used authenticity to refer to the reality and truthfulness of a product, which in turn, influences consumers' trust in the brand and the brand's growth within the marketplace (Napoli, Dickinson, \& Beverland, 2014). Some features of digital video that have been shown to promote feelings of authenticity are already implemented by the Deep Look creators, such as using a consistent host (Welbourne \& Grant, 2016). However, there are other authenticity-promoting features that are not currently used by Deep Look, such as posting content that is raw and unproduced, similar to content posted by YouTube users who are not media professionals. Researchers Wahl-Jorgensen, Williams, and Wardle (2010), for example, found among their focus group participants that, "there is clearly a feeling that if something has been filmed, photographed, or reported on by a member of the public this makes it somehow more believable" (p. 184). Media professionals may find that viewpoint surprising and counterintuitive given that industry workers and experts dedicate an abundant amount of time studying, developing, and improving their craft. However, a separate study reported that younger viewers-teenagers and pre-teenspreferred YouTube videos because, they say, they relate to the authenticity of content that is user generated (Holland, 2016). Therefore, unproduced content, with its relaxed, unpolished style, may increase audiences' perceptions of authenticity in particular.
Behind-the-scenes slideshows may be a less resource intensive way to provide BTS content. In addition to examining whether attaching unproduced BTS video footage to the original episodes (as means of simulating amateur usergenerated content) would increase perceptions of connectedness and authenticity, we were also interested in seeing whether a slideshow of BTS photos would do the same.

Taking onsite photos and creating a short BTS slideshow to follow episodes is significantly less resource intensive than onsite filming and producing full BTS episodes. If benefits of BTS slideshows match (or exceed) that of produced or unproduced BTS videos, then Deep Look producers may consider slideshows a more cost-effective BTS option.

\section{The effects of BTS content on the target} audience. More important than aiming to increase feelings of connectedness, perceptions of authenticity, and demonstrations of engagement is increasing these among the target audience. Deep Look is a show created for people who are science curious. The BTS content, in particular, is created for the most ardent Deep Look fans. Although increased positive outcomes among currently unengaged audiences are, of course, a desirable effect, they cannot be achieved at the cost of desirable outcomes among the target audience nor the missing audience (science-curious women). Therefore, we also examine differences in our study outcomes based on both science curiosity and gender.

\section{Study Design, Objectives, and Creation}

We conducted a survey experiment to examine whether watching behind-the-scenes content influences participants' perceptions of the Deep Look identity or affects their engagement with the series. We also aimed to determine whether there were significant differences between the varieties of BTS content (e.g., produced BTS episodes, unproduced video footage, or a slideshow), given that the produced BTS episodes require a lot of resources, and some argue that unproduced content may increase perceptions of authenticity (WahlJorgensen et al., 2010; Holland, 2016).

Qualtrics Research Services recruited participants $(N=1,045)$ for the study using quota sampling to approximate national representativeness. 


\section{Measures}

After first completing the science curiosity questionnaire (Kahan et al., 2017), participants were randomly assigned to one of ten conditions that determined which original episode they saw and which variety of BTS content was appended.

Participants were randomly assigned to watch one of two episodes: "Decorator Crabs Make High Fashion at Low Tide" or "A Sand Dollar's Breakfast is Totally Metal." Following the episode, participants could have seen one of five different BTS content types.

That is, participants were randomly assigned into one of five conditions in which they saw...

- only the original episode,

- the original episode that opened with the series narrator introducing the episode (i.e., the standup + original),
- the original episode with a slideshow of behindthe-scenes pictures (i.e., the original + pictures),

- the original episode with unproduced behindthe-scenes footage (i.e., the original + unproduced), or

- the original episode with the produced behind-the-scenes episode (i.e., the original + produced).

Participants were introduced to the episode with the following text:

As you know, companies and individuals produce video content on a wide variety of topics for people with a wide variety of interests. We will now select a short story for you to watch, then we will ask you some questions about the video.

Press play to start the video.

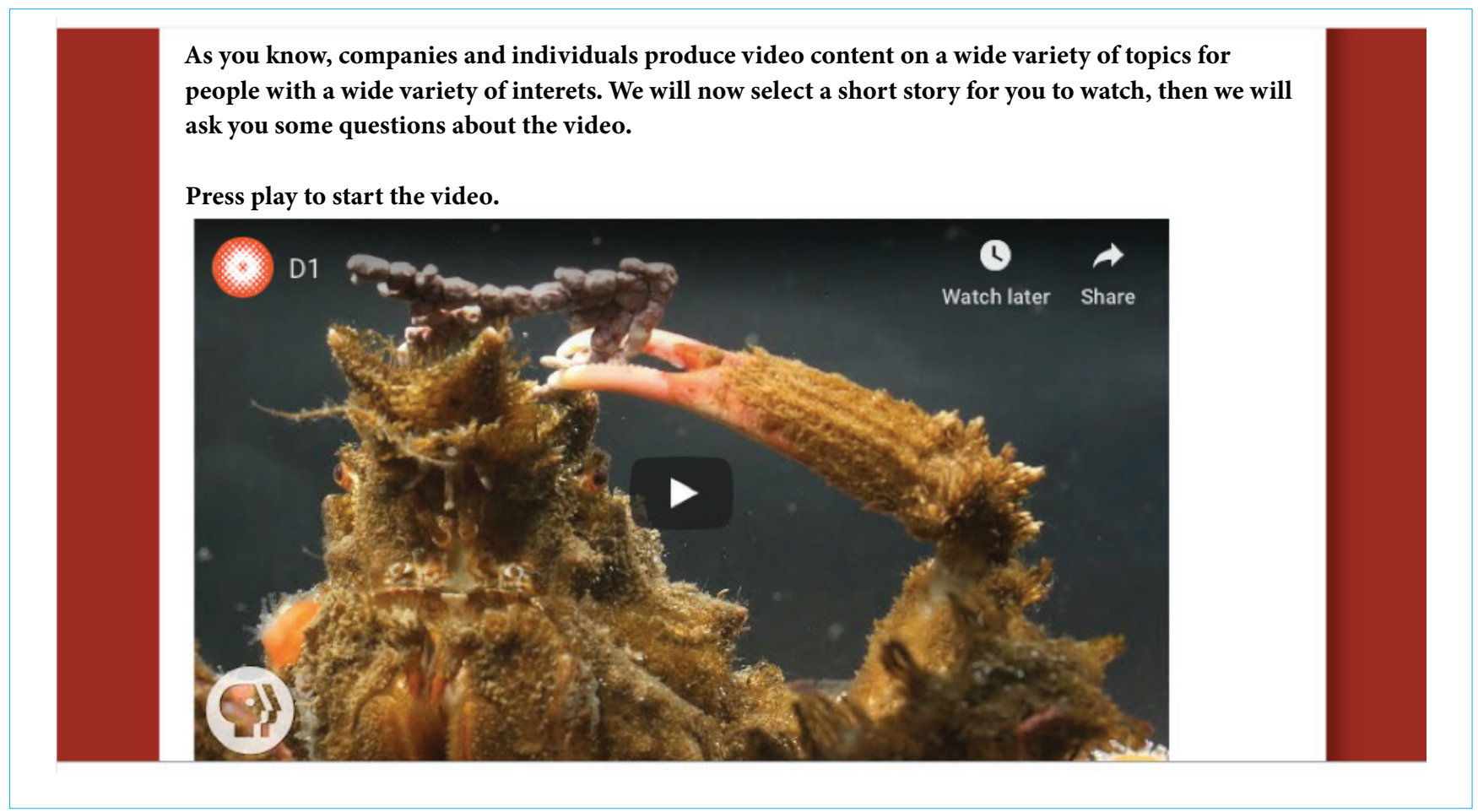

Figure 1. Screenshot from the survey. 
We used an embedded timer feature in the survey software to require participants to stay on the page for the duration of the video. Recognizing that forcing participants to stay on a page doesn't guarantee that they watched the video, we asked participants how closely they paid attention to the video during the battery of questions measuring subjective engagement. Notably, because we forced participants to stay on the page for the duration of the video, we did not include watch time as part of the behavioral engagement indicators.

Connectedness. After watching the video, participants were asked 10 questions aiming to determine how connected they feel towards Deep Look. For example, participants were asked whether they believe that they could be friends with the narrator/ production crew members of Deep Look, whether they'd like to have Deep Look memorabilia (e.g., stickers, t-shirts), and whether watching Deep Look puts them in a better mood. These items were combined into a scale of connectedness. ${ }^{2}$

Engagement. Next, participants responded to the subjective and objective engagement indicators that were also present in the prior Deep Look studies. Participants were asked: how interesting, informative, and surprising they found the video; to list up to 10 questions that they had about the video; if they wanted a link to share the video; if they would like to provide their email address to subscribe to the Deep Look newsletter; if they wanted to receive updates about Deep Look content; and whether they had any comments to provide about the video. These items were combined into a scale of engagement. ${ }^{3}$

Authenticity. Finally, participants were asked eight questions about the authenticity of Deep Look's identity (or brand). Brand authenticity questions mirror credibility questions but focus on a brand instead of a person. Item examples are "Deep Look guarantees satisfaction," "I feel confident in the quality of Deep Look," and "I think Deep Look is honest." These items were combined into a scale of authenticity. ${ }^{4}$

Afterward, participants answered some standard demographic questions as well as questions about their use of YouTube. The items from this survey are available in the appendix.

\section{Hypotheses and Inference Strategy}

The primary aim of this study was to determine whether there are measurable benefits for the inclusion of BTS content at the end of an episode, compared to the original episode alone. Should the benefits in connectedness, authenticity, and/or engagement be significantly higher among those who saw BTS content than among those who saw only the original episode, then we have found support for the hypothesis that providing BTS content is beneficial.

As stated previously, it is also important that we ensure that any benefits seen are present, at least, among the Deep Look target audience. That is, benefits among the science-curious audiences are more desirable than benefits among those who are less science-curious. Equally important is that any benefits observed among the less science curious audience are not gained at the expense of Deep Look's relationship with those who are more science curious. Furthermore, benefits such as increasing connectedness, perceived authenticity, and engagement among Deep Look's missing audience (science-curious women), would be particularly useful.

To this end, we followed up our analysis (where science curiosity is treated as a continuous moderating variable) with an audience analysis where participants are split into quartiles based on their science curiosity score. See Figure 2.

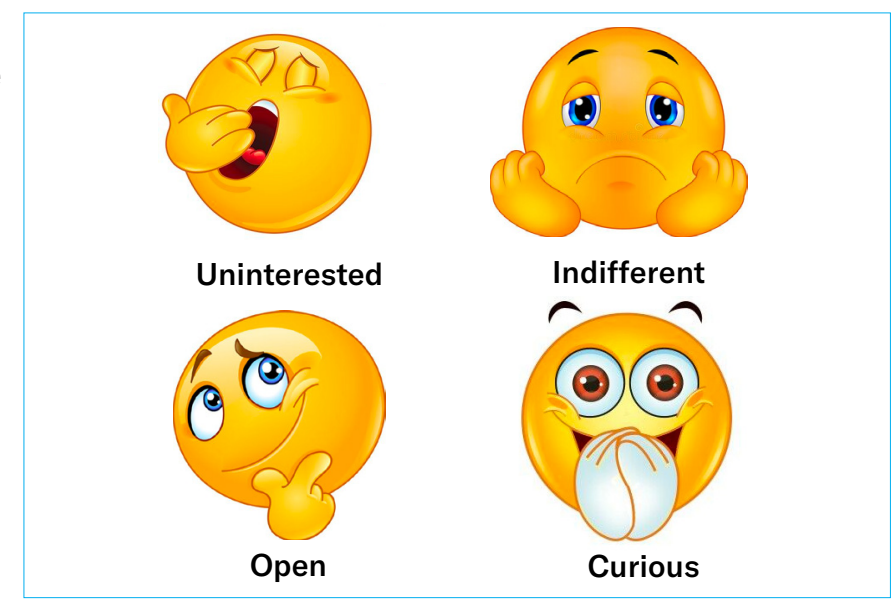

Figure 2. Four audiences based on science curiosity score quartiles: uninterested (bottom $25 \%$ ), indifferent $\left(25^{\text {th }}\right.$ to $50^{\text {th }}$ percentile), open ( $50^{\text {th }}$ to $75^{\text {th }}$ percentile), curious (top 25\%).

2 The connectedness scale was scored using item response theory, a graded-response model. Scores varied from -2.97 to 2.15 $(\mathrm{M}=-0.01, \mathrm{SD}=.97$, skew $=-0.09$, kurtosis $=0.18)$. See the appendix.

3 The engagement scale was scored using item response theory, a graded-response model. Scores varied from -2.81 to 2.3 $(\mathrm{M}=0, \mathrm{SD}=.92$, skew $=-0.2$, kurtosis $=-0.06)$. See the appendix.

$4 \quad$ The authenticity scale was scored using item response theory, a graded-response model. Scores varied from -3.06 to 1.74 $(\mathrm{M}=0.04, \mathrm{SD}=.87$, skew $=0.01$, kurtosis $=-0.02)$. See the appendix. 


\section{Study Results}

The study generated several principal findings central to the study hypotheses as well as secondary findings of interest (which do not address our questions for this behind-the-scenes study, specifically, but provide relevant information of interest). We describe these two sets of findings separately.

\section{Principal findings}

a. There does not appear to be any measurable benefits to attaching the produced behind-thescenes episodes to the original episodes.

Science-curious participants who watched the produced behind-the-scenes video after the original video reported similar levels of connectedness, authenticity, and engagement as sciencecurious people who only saw the original episode.
First, we found no statistically significant differences in reported connectedness between participants who saw the produced behind-thescenes content and participants who saw only the original episode. Notably, however, the follow-up audience analysis suggests that science-open women in the "produced" condition reported greater connectedness than science-open women in the "unproduced" condition. See Figure 3.

Second, although there is a statistical difference in reported perceptions of authenticity between participants who saw the produced BTS content and the participants who saw only the original episode (conditional on gender), the difference exists primarily among those participants with average or lower science curiosity-i.e., those outside Deep Look's main target audience, science curious individuals.

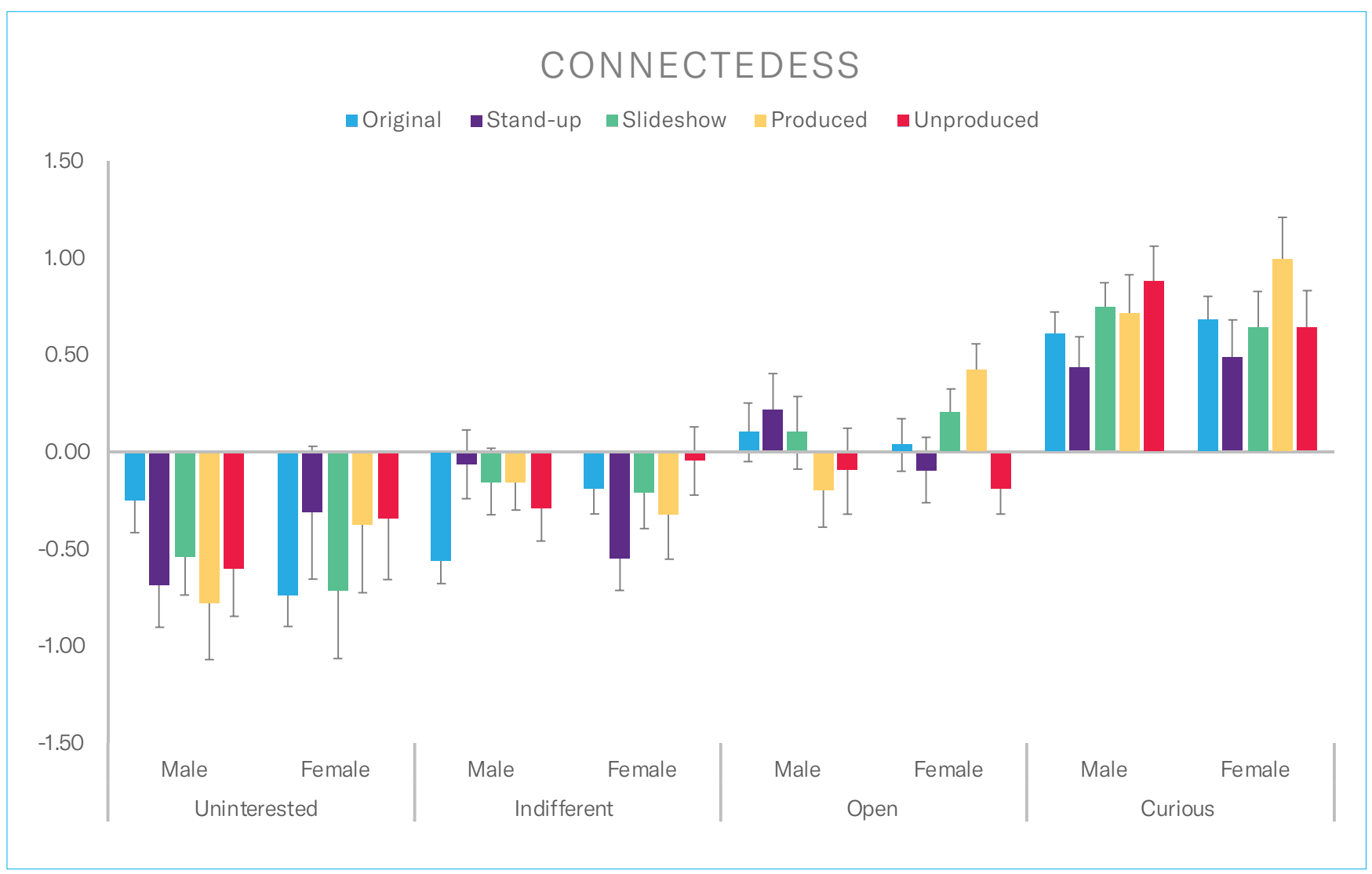

Figure 3. Visualization of the interaction between type of BTS content, science curiosity, and gender, when predicting participants' feelings of connectedness with the series narrator and the production crew members. 


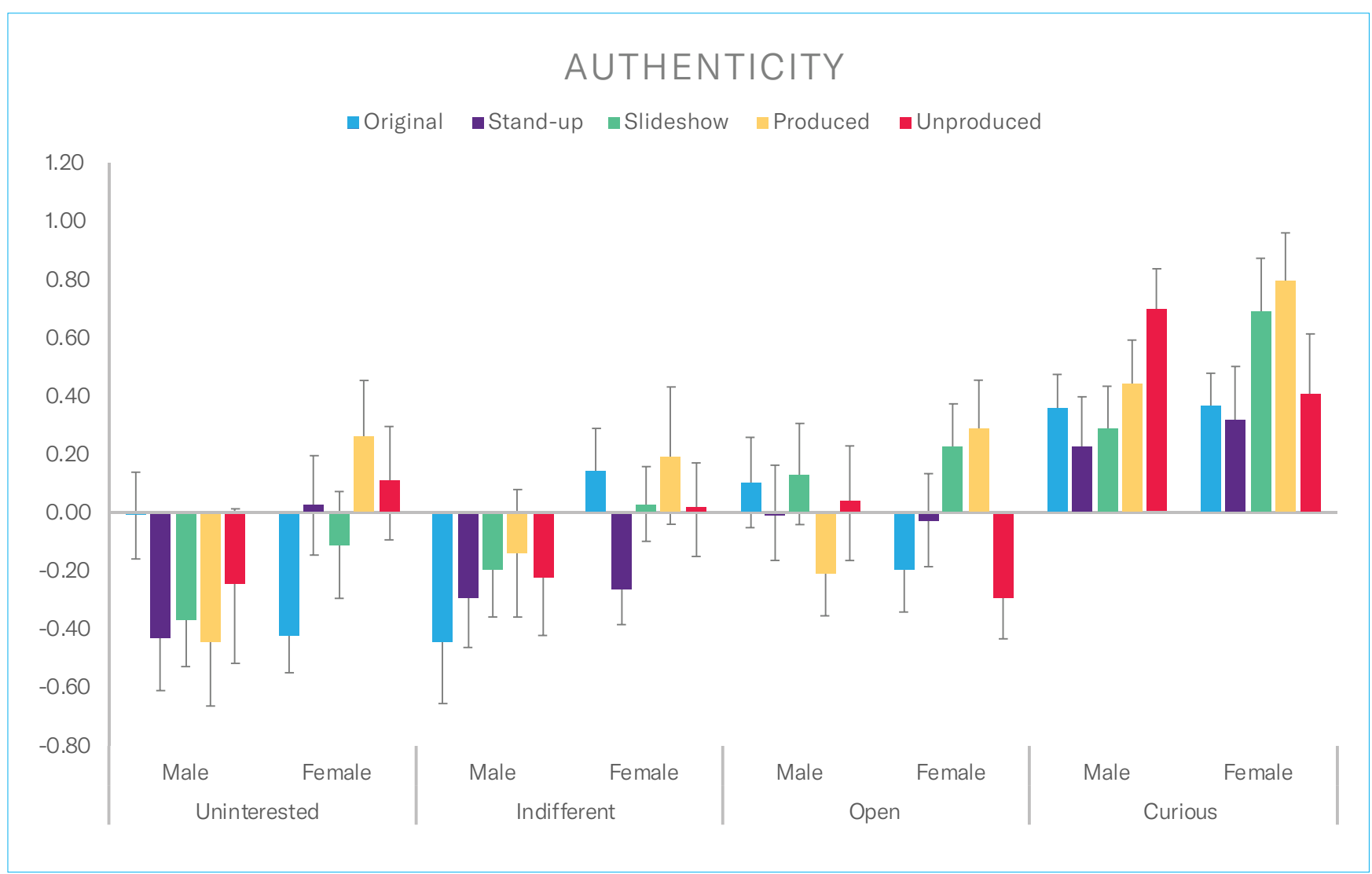

Figure 4. Visualization of the three-way interaction effect between type of BTS content, science curiosity, and gender, when predicting participants' perceptions of authenticity.

Follow-up audience analyses suggest that there is a marginal difference among uninterested women who saw the produced BTS content compared to uninterested women who saw only the original episode. Moreover, there was a marginal difference among open women who saw the produced BTS content compared to open women who saw the unproduced BTS content. See Figure 4.

Furthermore, there are no statistically significant differences in engagement based on whether participants watched the produced BTS video compared to watching only the original episode.

However, follow-up audience analyses suggest that there are significant differences in engagement among uninterested women in the slideshow condition compared with uninterested women in the stand-up condition.

\section{b. The BTS slideshow may be a more resource- efficient way to increase engagement and perceptions of authenticity.}

As established earlier, the photo slideshow is a less resource-intensive way of providing BTS content to viewers. First, the desired outcomes of connectedness, authenticity, and engagement did not vary significantly between the slideshow condition and the produced condition, generally. Second, the photo slideshow was associated with positive connectedness, authenticity, and engagement among science open and science curious women. Third was also high engagement among science indifferent women who saw the photo slideshow. This latter finding suggests that the BTS slideshows may be a way to reach new audiences.

\section{c. Unproduced BTS videos may have negative consequences for women who are science open.}

Women who are science open and science curious who were in the unproduced condition demonstrated either marginally lower or statistically lower connectedness, authenticity, and engagement than comparable women in the produced condition. 


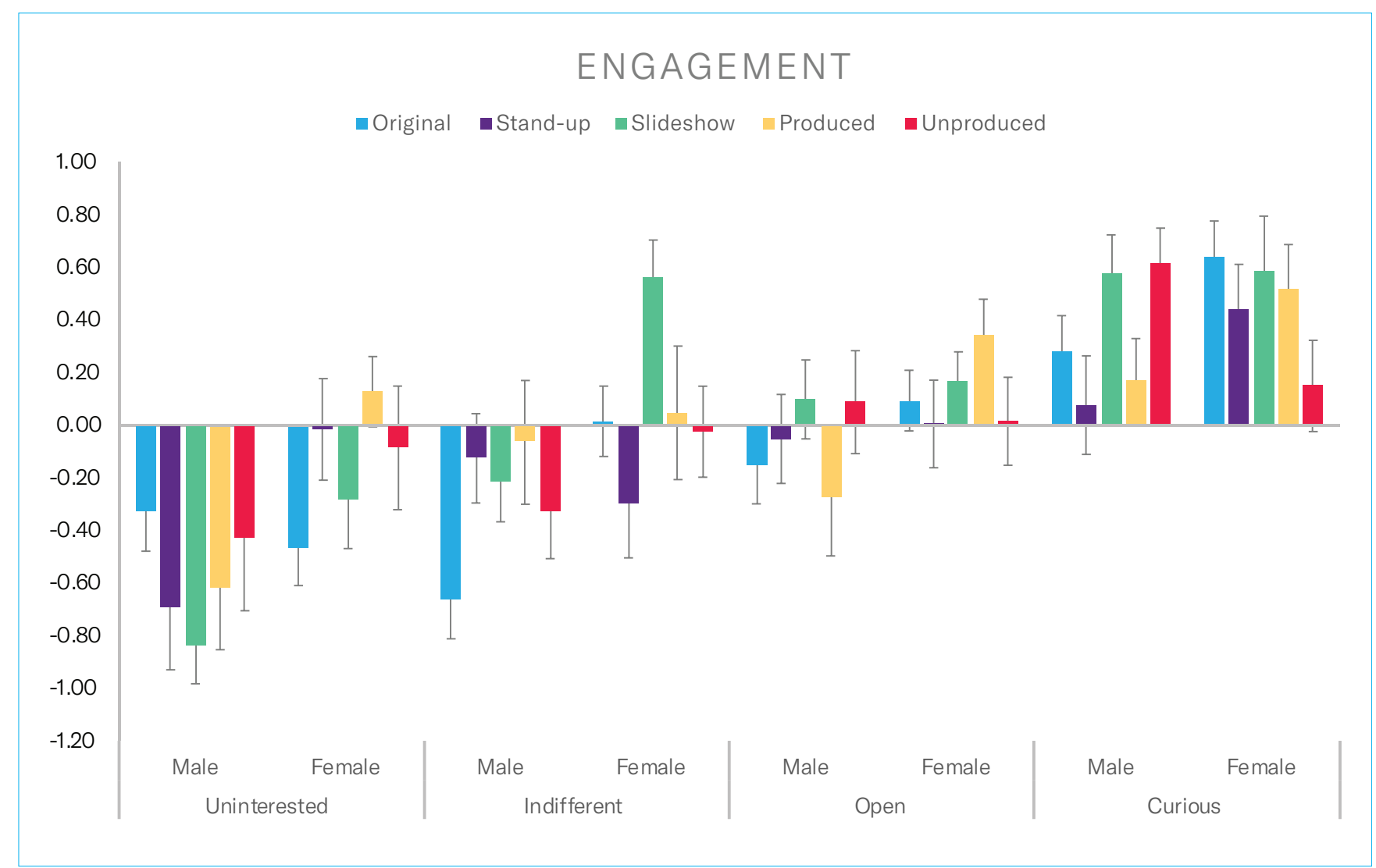

Figure 5. Visualization of the three-way interaction between type of BTS content, science curiosity, and gender on participants' engagement. 


\section{Secondary findings}

In addition to the principal findings, we report some secondary findings of interest.

a. Science curiosity is a strong predictor of each of the outcome variables. As stated in our last report, science curiosity (as measured by the SCS, Kahan et al., 2017; Kahan, 2019) is a powerful predictor for identifying people who enjoy consuming science media. Given that science-curious individuals compose the target audience for Deep Look, it is perhaps unsurprising (and definitely reassuring) that those with higher science curiosity report greater connectedness, perceived authenticity, and engagement across all different content types. See Figure 6.

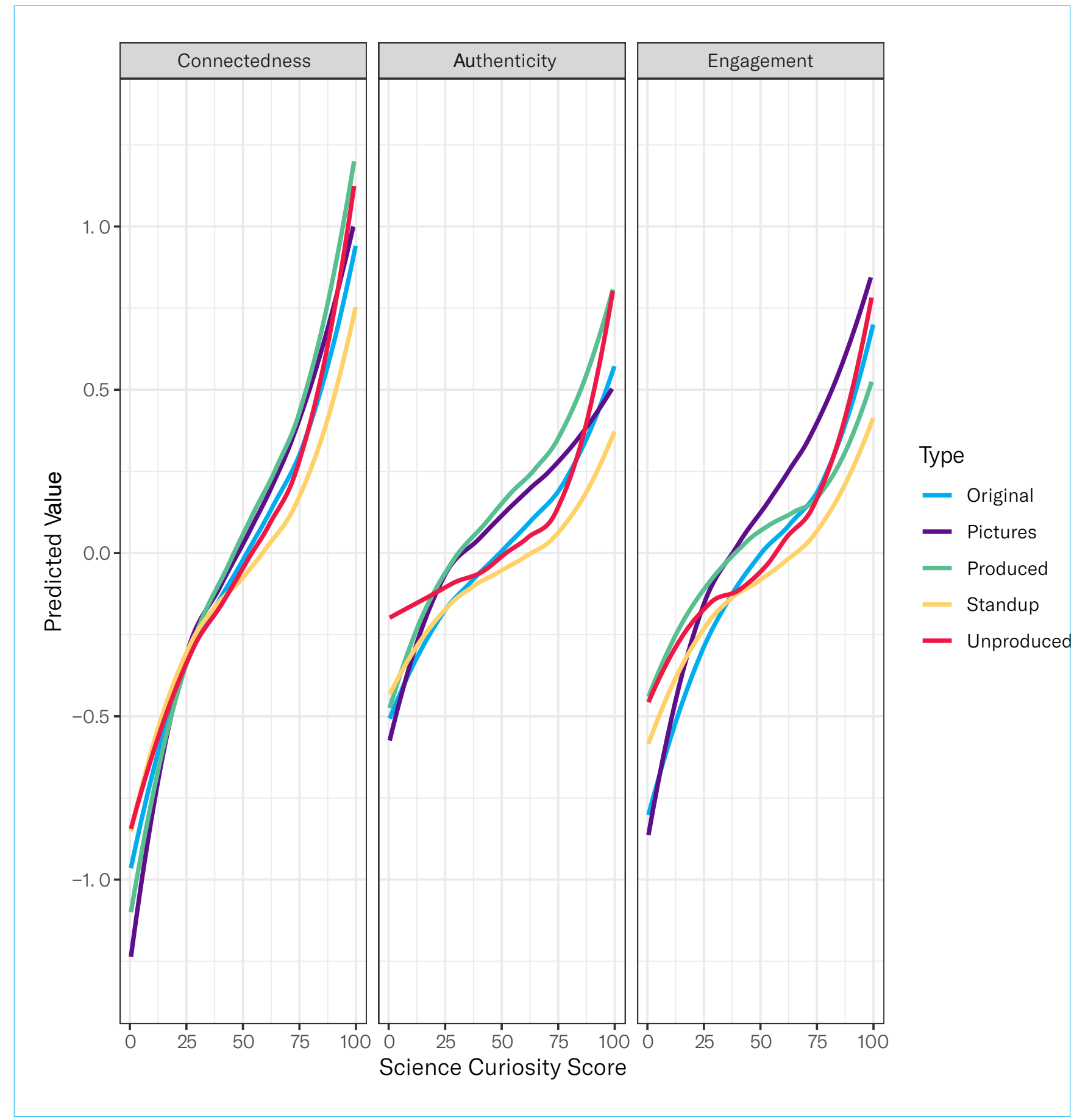

Figure 6. Science curiosity score strongly predicts each of the outcome variables in each of the conditions. LOESS curves are shown. 
b. There is a gender difference in science curiosity. Replicating our prior work, there is a gender difference in science curiosity (e.g., Kahan, 2019).
Males are 1.67 times more likely than females to score in the top quarter of science curiosity scores (the "science curious" audience).

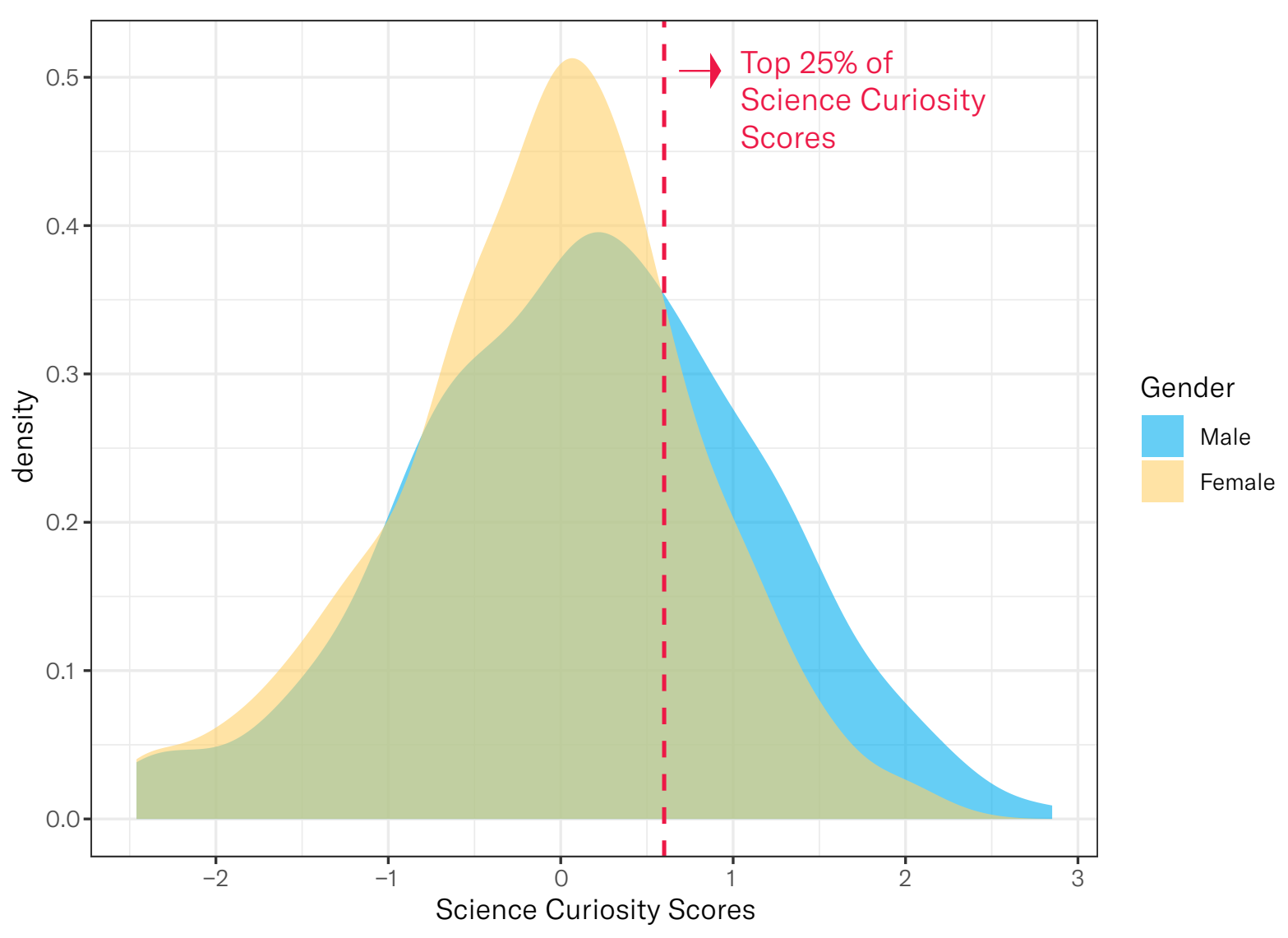

Figure 7. Distribution of science curiosity scores for males and females. Males are 1.67 times more likely to score in the top quarter (science curious audience) than females. Scores to the right of the orange dashed line are in the top $25 \%$ of SCS scores. 
c. Millennials and Generation X are more science curious than Baby Boomers. Millennials are 2.9

times more likely (and GenX is 2.8 times more likely) than Baby Boomers to score in the top quarter of science curiosity scores (the "science curious" audience).

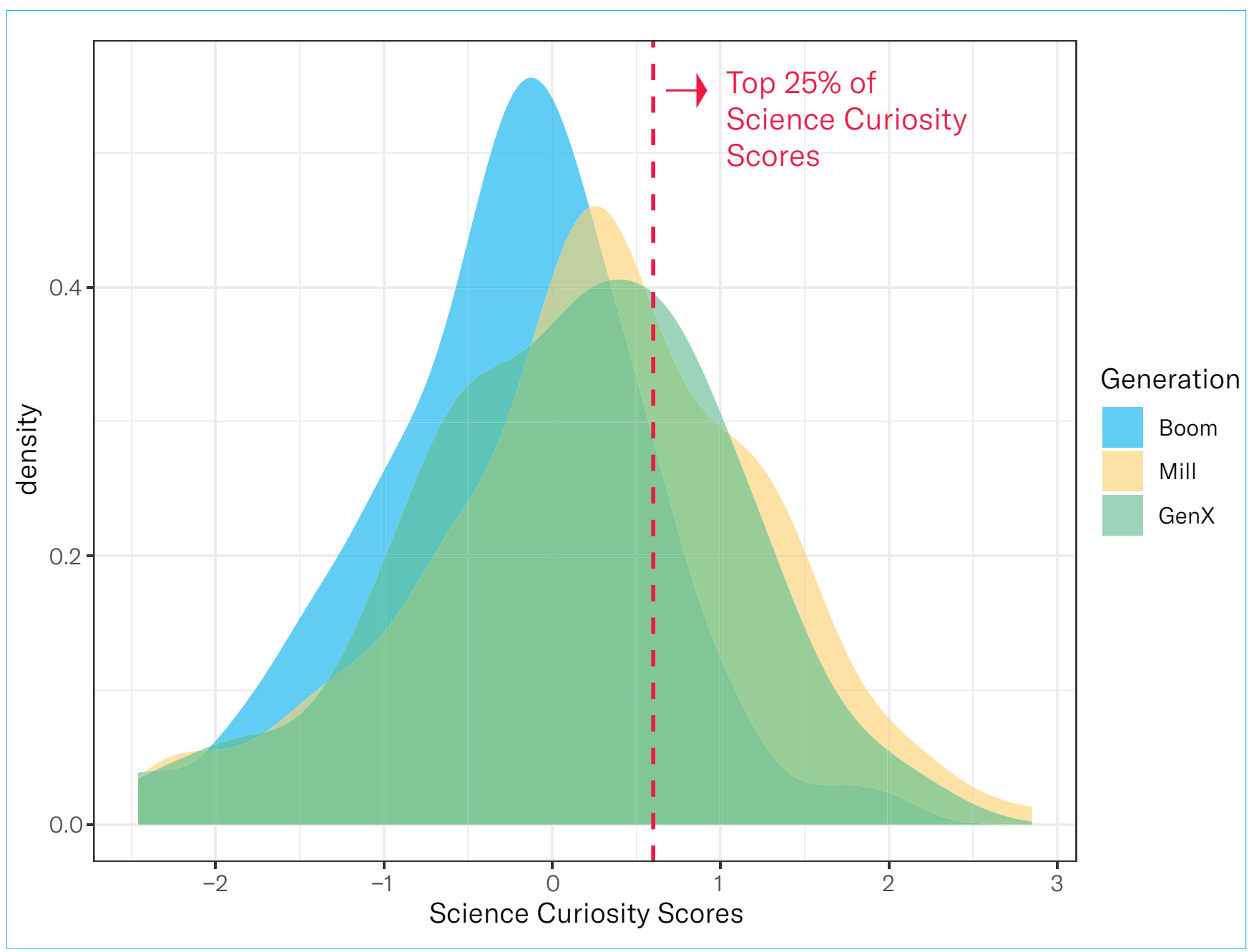

Figure 8. Distribution of science curiosity scores for Baby Boomers, Generation X and Millennials. Compared to Baby Boomers, Millennials are 2.9 times more likely (and GenX is 2.8 times more likely) to score in the top quarter of science curiosity scores. Scores to the right of the orange dashed line are in the top $25 \%$ of SCS scores. 


\section{E. Analysis and Interpretation}

As with prior Cracking the Code studies, we found that the Science Curiosity Scale (Kahan et al., 2017) strongly predicted how participants perceived and engaged with a variety of Deep Look episodes and content. Thus, the SCS scale continues to serve as a valuable tool for estimating who the target audiences for science content ought to be. We also expanded on our understanding of how different genders engage with science content and in this study found gender differences in perceptions of various Deep Look BTS formats and participants' willingness to engage with the content.

The driving questions for this study were (1) whether there are measurable benefits to providing audiences with behind-the-scenes content and, if so, (2) whether the benefits from providing high quality produced behind-the-scenes episodes are greater than those from providing other, less resourceintensive types of behind-the-scenes content.

We looked at three potential benefits of providing BTS content: increasing audiences' feelings of connectedness with the narrator and production team, increasing audiences' perceptions of the show's authenticity, and increasing audiences' engagement with the episode and the series. Engagement remains a key online metric for digital content producers as it opens the door for media outlets to grow their audiences, exposing viewers to additional science content which ultimately can lead to more loyal audiences/fans.

Notably, this study appended the BTS content to the end of the original episode. This decision was made based on concerns that posting different types of videos to the Deep Look YouTube channel (other than the original episodes) may negatively influence the way the channel is treated by the YouTube algorithm. However, since the initial construction of this study, YouTube has added a "Community Tab" that provides a potentially more appropriate venue for BTS content.

Future studies examining BTS content ought to examine whether BTS content may drive audiences to watch the original content (as opposed to solely serving as supplemental engagement opportunities).

Several of this study's findings, when viewed collectively, suggest that women evaluate professionally produced behind-the-scenes video more favorably than raw and less-polished BTS material.
First, our statistical models suggest that science curiosity is a weaker predictor of connectedness, authenticity, and engagement for women than men when the participants viewed the unproduced BTS footage compared to when participants viewed just the original footage. Second, our audience analysis suggests that women who are open to science reported greater connectedness (and marginally more perceived authenticity) in the produced compared to the unproduced conditions. Because the BTS content was attached to the original episode, these findings beg the question of whether the inclusion of a more amateur-style BTS video negatively impacts the overall perception of the original Deep Look episode. Yet, the inclusion of the high quality, produced BTS episodes don't generate significantly more positive outcomes than other types of BTS content (or even compared to the original episode alone), especially when looking at the target audience (science-curious individuals). These results taken together show that the benefits of expending resources to professionally create BTS videos may not generate an exceptional return on investment.

Though science-curious women may be Deep Look's missing audience, BTS footage appealed to women who were less science curious.

Science-curious men and women already reported high levels of connectedness, perceived authenticity, and engagement after watching only the original video. The appending of BTS content to the original videos did not yield significant increases in these three outcome variables for that audience. However, BTS content granted benefits among less science-curious women-those who are open to science, and in some cases, women who are indifferent to science (see Figure 2). This suggests an unexpected advantage of appending some type of BTS content to a Deep Look episode and/or using BTS content on other social platforms to engage a new audience and drive interest in Deep Look.

Yet, how do we get women of lower science curiosity to click on the episode in the first place? The experimental data from a prior Cracking the Code (CTC Report 1) study showed that higher science-curious individuals chose to view their assigned Deep Look episode more than those with lower science curiosity when given the choice of whether to watch (Kahan, 2019). The design of this study differed in that we forced participants to watch the episode that we assigned them, and they did not have the option to opt-out of viewing the 
episode. Nevertheless, the data suggested that women lower in science curiosity reacted favorably to specific Deep Look BTS content once they saw the clip. Studies to explore story elements or engagement tactics that close the gender gap is a logical step in the CTC line of projects.

The producers of Deep Look, of course, don't want to lose their male audience while searching out methods to decrease the gender disparity on the series' YouTube videos. The experimental data from this study produced a minuscule number of statistically significant results among science-curious men. However, two findings that may appeal to producers are that science-curious men who viewed the episode with the BTS slideshow perceived the clip to be more authentic and demonstrated higher engagement than high-science-curiosity men who only saw the original episode. While these same measures did not vary among high-science-curiosity women, looking at the glass half full, the data did not show that the BTS slideshow negatively impacted sciencecurious women's engagement or perception of authenticity. Therefore, the BTS slideshow appears to be a resource-friendly alternative to the produced BTS video, even if its impact is not substantial among women of higher science curiosity.

An unexpected study finding was that the appearance of Deep Look's female host introducing the two episodes did not generate high feelings of connectedness, perceived authenticity, or more engagement than watching the original episodes with only the host's voiceovers. This same result was reported in a prior study examining the effectiveness of a female host in engaging a female audience (Amarasekara and Grant, 2019). One limitation of our study is that the Deep Look study participants only viewed one episode, and the time that they saw the narrator addressing them through the camera was mere seconds. So, that may not have been enough time or enough episodes for the audience to feel more connected with the host and thus the media product. Prior research suggested that relationships with media characters strengthen with repeated exposure (e.g., Eyal \& Cohen, 2006). We surmise that seeing the host appear only once on-camera introduce the episode may not have been enough exposure time for viewers to generate considerable PSI.

On the other hand, the BTS content provided more than just a "talking head." Viewers could see the crew members interacting with each other or with the creatures. The crew's facial expressions varied based on the situation. Perhaps, to these viewers and study participants, Deep Look became more than just a show about tiny creatures; viewers could see the time, energy and thoughtfulness expended on producing a short episode. A look behind the scenes humanized the Deep Look identity and connected viewers more fully, similar to the assessment of another study looking into these issues by Point in Time Studios ("Why you need," 2018).

Overall, the results of this study suggest that one size does not fit all. In other words, media designed to engage new audiences needs to be differentiated for the target audience. Men and women lower in science curiosity will respond to variations of Deep Look content differently than those who are more science curious. In many instances, women and men, in general, have different perceptions and engagement responses. If KQED's targeting its main missing audience for Deep Look, which in this case is science-curious women, then this study and report have provided suggestions on how to better connect and engage with this group through production and engagement activities for its Deep Look series. 


\section{F. REFERENCES}

Amarasekara, I., \& Grant, W. J. (2019). Exploring the YouTube science communication gender gap: A sentiment analysis. Public Understanding of Science, 28(1), 68-84.

Daniels, J. (2014). How to increase engagement with behind-the-scenes content. Callahan Agency. Retrieved from: https://callahan.agency/how-to-increase-engagement-with-behind-the-scenes-content/

Dibble, J. L., Hartmann, T., \& Rosaen, S. F. (2016). Parasocial interaction and parasocial relationship: Conceptual clarification and a critical assessment of measures. Human Communication Research, 42(1), 21-44.

Eris, S. (2019, April 17). KQED and partners receive a \$3 million National Science Foundation grant. KQED. Retrieved from https://ww2.kqed.org/about/2019/04/17/kqed-and-partners-receive-3-million-nationalscience-foundation-grant/

Giles, D. C. (2002). Parasocial interaction: A review of the literature and a model for future research. Media psychology, 4(3), 279-305.

Holland, M. (2016). How YouTube developed into a successful platform for user-generated content. Elon Journal of Undergraduate Research in Communications, 7(1). Retrieved from http://www.inquiriesjournal. com/articles/1477/how-youtube-developed-into-a-successful-platform-for-user-generated-content

Kahan, D. M. (2019, November 20). A Deep Look at gender disparity: A scientific investigation into the science communication of KQED's nature series. KQED. Retrieved from https://drive.google.com/file/d/1PQ1PEukuz Rgv3 icmLxw58VbtPkfpBj/view

Kahan, D. M., Landrum, A., Carpenter, K., Helft, L., \& Hall Jamieson, K. (2017). Science curiosity and political information processing. Political Psychology, 38, 179-199.

Landrum, A. R. (2019, May 3). Experimenting with science news headline format to maximize engagement. KQED. Retrieved from https://ww2.kqed.org/about/2019/05/03/experimenting-with-science-news-headline-format-to-maximize-engagement/

Lush Content (2020). Behind the scenes of video production: The benefits of sharing insight into your businesses. Lush: The Content Agency. Retrieved from https://lushthecontentagency.com/blog/behind-thescenes-video-production-the-benefits-of-sharing-insight-into-your-business/

McCroskey, J. C., \& Teven, J. J. (1999).Goodwill: A reexamination of the construct and its measurement. Communication Monographs, 66, 90-103.

Napoli, J., Dickinson, S. J., Beverland, M. B., \& Farrelly, F. (2014). Measuring consumer-based brand authenticity. Journal of Business Research, 67(6), 1090-1098.

O'Brien, M. (2018, April 5). The value of behind-the-scenes content in marketing. NextPage. Retrieved from: https://gonextpage.com/2018/04/05/the-value-of-behind-the-scenes-content-in-marketing/

Patino, A., Kaltcheva, V. D., \& Smith, M. F. (2011). The appeal of reality television for teen and pre-teen audiences: The power of "connectedness" and psycho-demographics. Journal of Advertising Research, 51(1), 288-297.

Rubin, A. M., Perse, E. M., \& Powell, R. A. (1985). Loneliness, parasocial interaction, and local television news viewing. Human communication research, 12(2), 155-180.

Russell, C. A., Norman, A. T., \& Heckler, S. E. (2004). The consumption of television programming: Development and validation of the connectedness scale. Journal of Consumer Research, 31(1), 150-161. 


\section{F. REFERENCES, CONTINUED}

vidwheel (2019, June 3). Video content marketing: Go behind the scenes. vidwheel.com Retrieved from: https://vidwheel.com/2019/06/03/go-behind-the-scenes/

Wahl-Jorgensen, K., Williams, A., \& Wardle, C. (2010). Audience views on user-generated content: exploring the value of news from the bottom up. Northern Lights: Film \& Media Studies Yearbook, 8(1), 177-194.

Welbourne, D. J., \& Grant, W. J. (2016). Science communication on YouTube: Factors that affect channel and video popularity. Public Understanding of Science, 25(6), 706-718.

Why you need behind-the-scenes content on your social media. (2018, September 30). Point in Time Studios. Retrieved from https://pointintimestudios.com/why-you-need-behind-the-scenes-content-on-yoursocial-medial 


\section{G. APPENDICES}

\section{Participants}

Participants were recruited by Qualtrics Research Services between November 1, 2019 and November 7, 2019. Quota sampling was employed to match demographic proportions to census levels for gender, race/ ethnicity, and age. Harder to reach samples (e.g., African Americans, Hispanics) were contacted first. We requested a sample of 1,000 participants.

\section{a. Drop Criteria}

A total of 2,124 participants opened the survey.

- 26 participants were not allowed to complete the survey for reporting both that they were under 18 and that they don't live in the U.S.

- 85 participants were not allowed to complete the survey for reporting that they were under 18.

- 27 participants were not allowed to complete the survey for reporting that they don't live in the U.S.

- 682 participants were dropped for opening but not completing the survey.

- 247 participants were dropped for incorrectly answering the attention check question, which simply asked them, "If you are reading this, choose 'somewhat agree."

- 12 participants were dropped for "speeding," which was defined as completing the survey in less than half of the median time it took for the sample to take the survey.

The final sample was 1,045 participants.

\section{b. Characteristics}

\section{Table 1. Participant Characteristics compared to Census}

\begin{tabular}{|c|c|c|}
\hline & CENSUS (\%) & OUR SAMPLE (\%) \\
\hline \multicolumn{3}{|l|}{ Age (for those 20 years and older) } \\
\hline 20 to 24 years & 6.7 & 10.09 \\
\hline 25 to 34 years & 13.8 & 18.68 \\
\hline 35 to 44 years & 12.6 & 17.48 \\
\hline 45 to 54 years & 13.0 & 17.08 \\
\hline 55 to 59 years & 6.7 & 8.89 \\
\hline 60 to 64 years & 6.2 & 8.79 \\
\hline 65 to 74 years & 9.1 & 15.18 \\
\hline 75 to 84 years & 4.6 & 3.60 \\
\hline 85 years and over & 1.9 & 0.20 \\
\hline \multicolumn{3}{|l|}{ Gender (for those 18 years and older) } \\
\hline Male & 48.7 & 45.0 \\
\hline Female & 51.3 & 54.2 \\
\hline \multicolumn{3}{|c|}{ Race (alone or in combination with other races) } \\
\hline White & 75.1 & 64.69 \\
\hline Black or African American & 14.1 & 13.68 \\
\hline American Indian/Alaska Native & 1.7 & 2.58 \\
\hline Asian & 6.6 & 6.12 \\
\hline Native Hawaiian/Pacific Islander & 0.4 & 0.67 \\
\hline Other & 5.6 & 1.15 \\
\hline \multicolumn{3}{|l|}{ Ethnicity } \\
\hline Hispanic or Latino (of any race) & 18.1 & 17.03 \\
\hline
\end{tabular}


Table 1. Participant Characteristics compared to Census (continued)

\begin{tabular}{|c|c|c|}
\hline & CENSUS (\%) & OUR SAMPLE (\%) \\
\hline \multicolumn{3}{|c|}{ Educational Attainment (for those 25 years and older) } \\
\hline Less than 9 th grade & 5.4 & 0.11 \\
\hline 9th to 12 th grade no diploma & 7.2 & 3.01 \\
\hline High school graduate or equivalency & 27.3 & 23.50 \\
\hline Some college, no degree & 20.8 & 22.94 \\
\hline Associate's degree & 8.3 & 17.93 \\
\hline Bachelor's degree & 19.1 & 23.16 \\
\hline Graduate or professional degree & 11.8 & 9.35 \\
\hline percent high school graduate or higher & 87.3 & 96.88 \\
\hline percent bachelor's degree or higher & 30.9 & 32.52 \\
\hline
\end{tabular}

\section{Experimental Manipulation}

Participants were randomly assigned into one of 10 conditions. In all the conditions, participants were shown a video clip (see example below). Participants were unable to advance to the next part of the survey for the length of time of the video, whether participants actually watched the video or not. See Figure X.

The conditions varied on the story (2 possibilities: decorator crabs, sand dollars) and type of behind-thescenes content (5 possibilities: original alone, produced video, unproduced video, photos, or the stand-up with host).

Table 2. Conditions and number of study participants in each condition.

\begin{tabular}{|c|c|c|}
\hline TYPE OF BTS GONTENT & DECORATOR CRABS & SAND DOLLARS \\
\hline Original & $n=144$ & $n=148$ \\
\hline + Produced Behind the Scenes & $n=85$ & $n=81$ \\
\hline + Unproduced Behind the Scenes & $n=92$ & $n=93$ \\
\hline + BTS Slideshow & $n=107$ & $n=103$ \\
\hline + Stand-up with Lauren & $n=102$ & $n=90$ \\
\hline
\end{tabular}

\section{Measures}

\section{a. Science Curiosity Scale}

Science curiosity was measured using the science curiosity scale (Kahan, Landrum, et al., 2017). Consistent with prior research, scores were calculated using item response theory. Scores ranged from -2.46 to 2.85 and were approximately normally distributed $(M=0.01$, Median $=0.06, S D=0.95)$. 


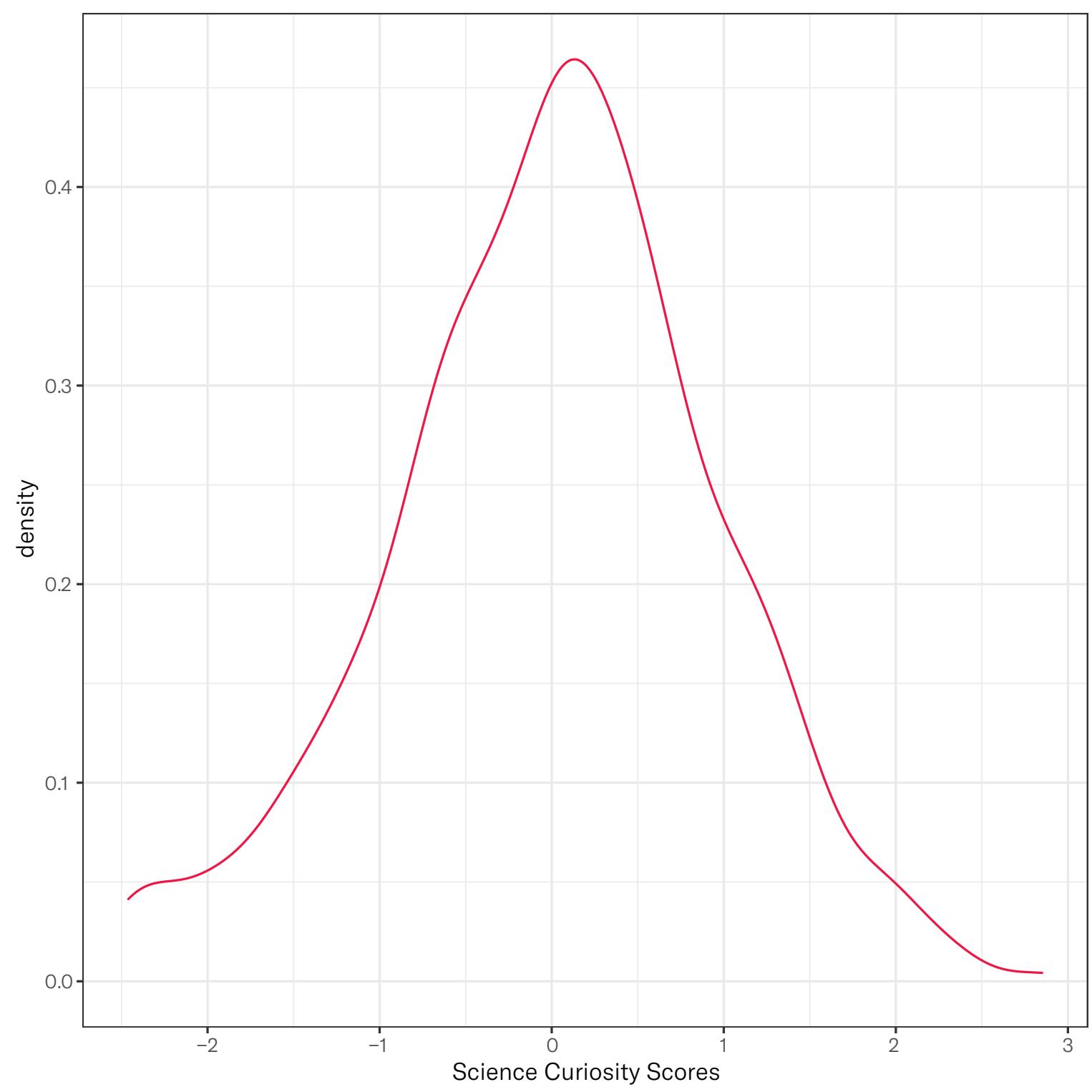

Figure 9. Distribution of science curiosity scores for this study sample.

\section{b. Connectedness}

Connectedness is conceptualized as the intensity of the relationship developed between TV viewers and the program and its characters - media personality (Russel, Norman, \& Heckler, 2004).

To measure connectedness, we modified the connectedness scale (Russel et al., 2004). In particular, we adjusted the questions to better fit with KQED's Deep Look identity.

A parallel analysis, optimal coordinates analysis, and scree test all suggest that our measure of connectedness is unidimensional.

The scale also has strong internal reliability (Cronbach's alpha $=0.92,95 \% \mathrm{Cl}[0.91,0.92])$.

As with the science curiosity scale, we scored the connectedness scale using item response theory. 
Scores ranged from -2.97 to $2.15(M=-0.01$, Median $=-0.05, S D=0.97)$, and were slightly negatively skewed (skew $=-0.09$ ).

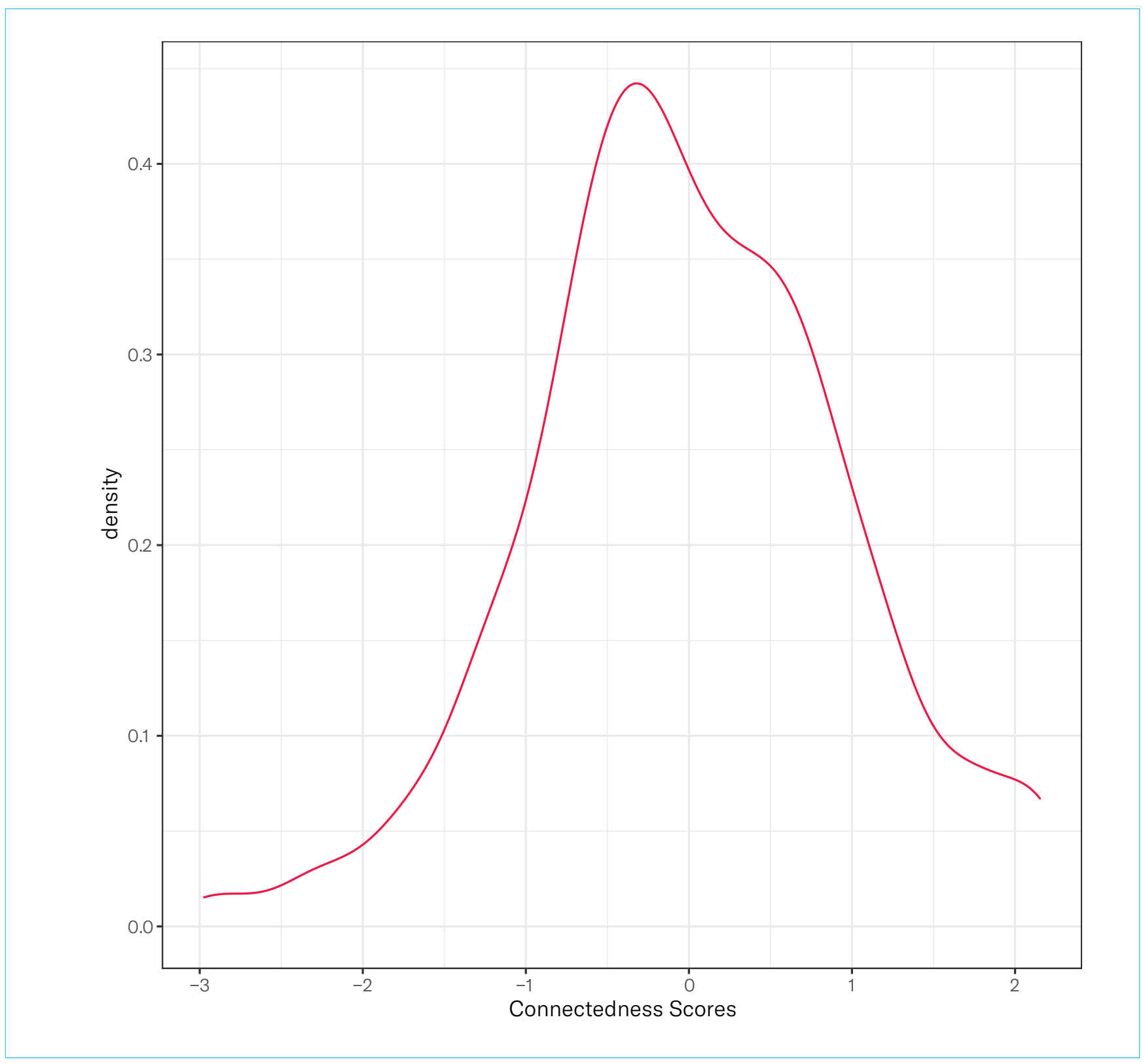

Figure 10. Distribution of connectedness scores for this study sample. 


\section{c. Authenticity}

Authenticity refers to the reality and truthfulness of the product, which should influence brand trust and growth within the marketplace (Napoli et al, 2014).

To measure authenticity, we modified the brand authenticity scale (Napoli et al., 2014). In particular, we adjusted the questions to align more closely with Deep Look's digital videos.

A parallel analysis, optimal coordinates analysis, and scree test all suggest that our measure of authenticity is unidimensional.

The scale also has strong internal reliability (Cronbach's alpha $=0.87,95 \% \mathrm{Cl}[0.85,0.88])$. The Cronbach's alpha would improve to .91 if the "no confidence" item was dropped.

As with the science curiosity scale, we scored the authenticity scale using item response theory. Scores ranged from -3.06 to $1.74(M=0.04$, Median $=0.01, S D=0.87)$.

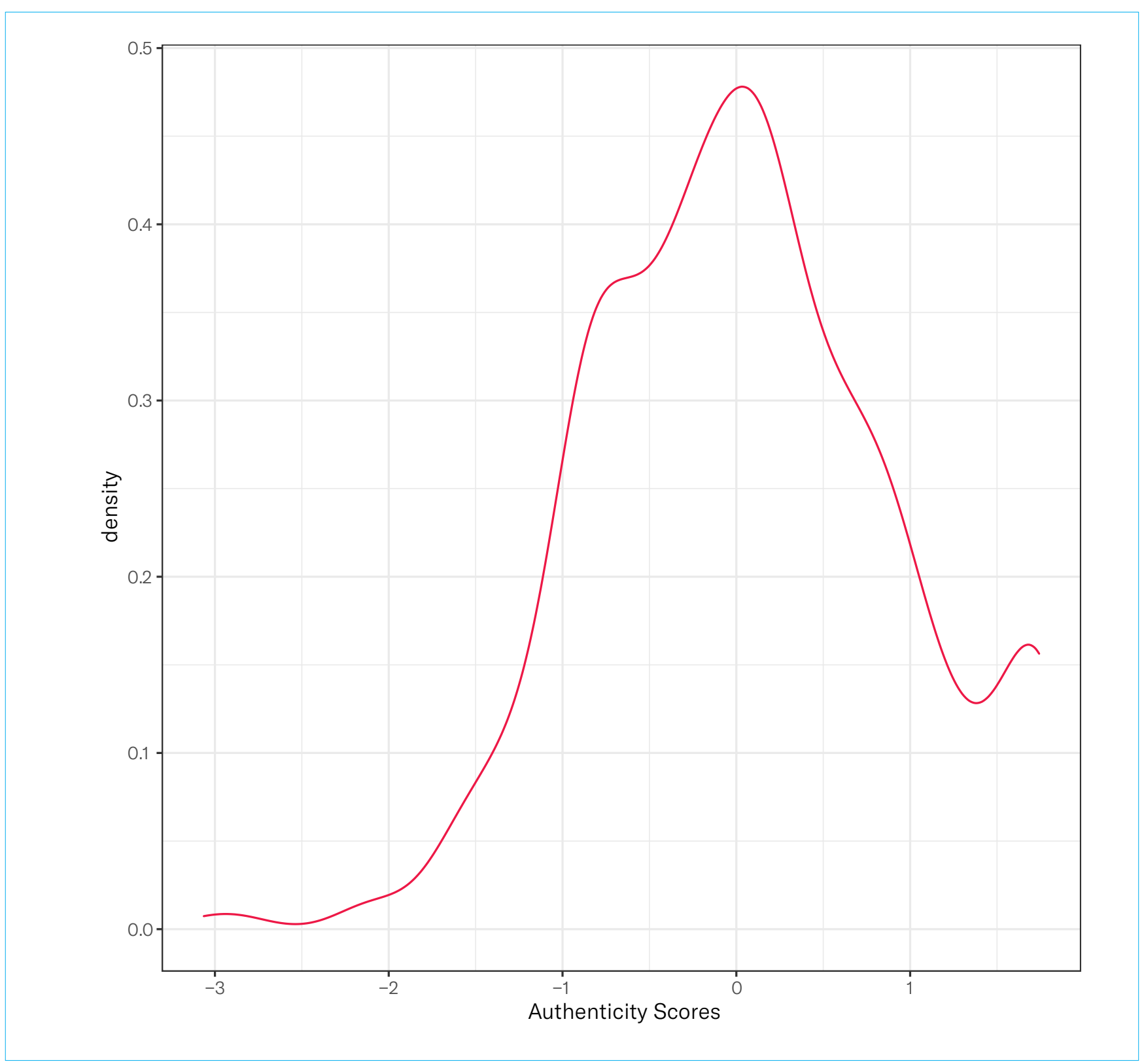

Figure 11. Distribution of authenticity scores for this study sample. 


\section{d. Engagement}

Of primary interest to KQED and members of its Deep Look team is the extent to which participants were engaged with the content.

To measure engagement, we combined both subjective and behavioral measures. Perhaps unsurprisingly, subjective engagement scores were higher than behavioral scores.

When combined using item response theory, the resulting factor scores were approximately normally distributed with a slight negative skew (skew $=-0.2)$. Scores ranged from -2.81 to $2.3(\mathrm{M}=0.0$, Median $=$ 0.04, SD $=0.92$ ).

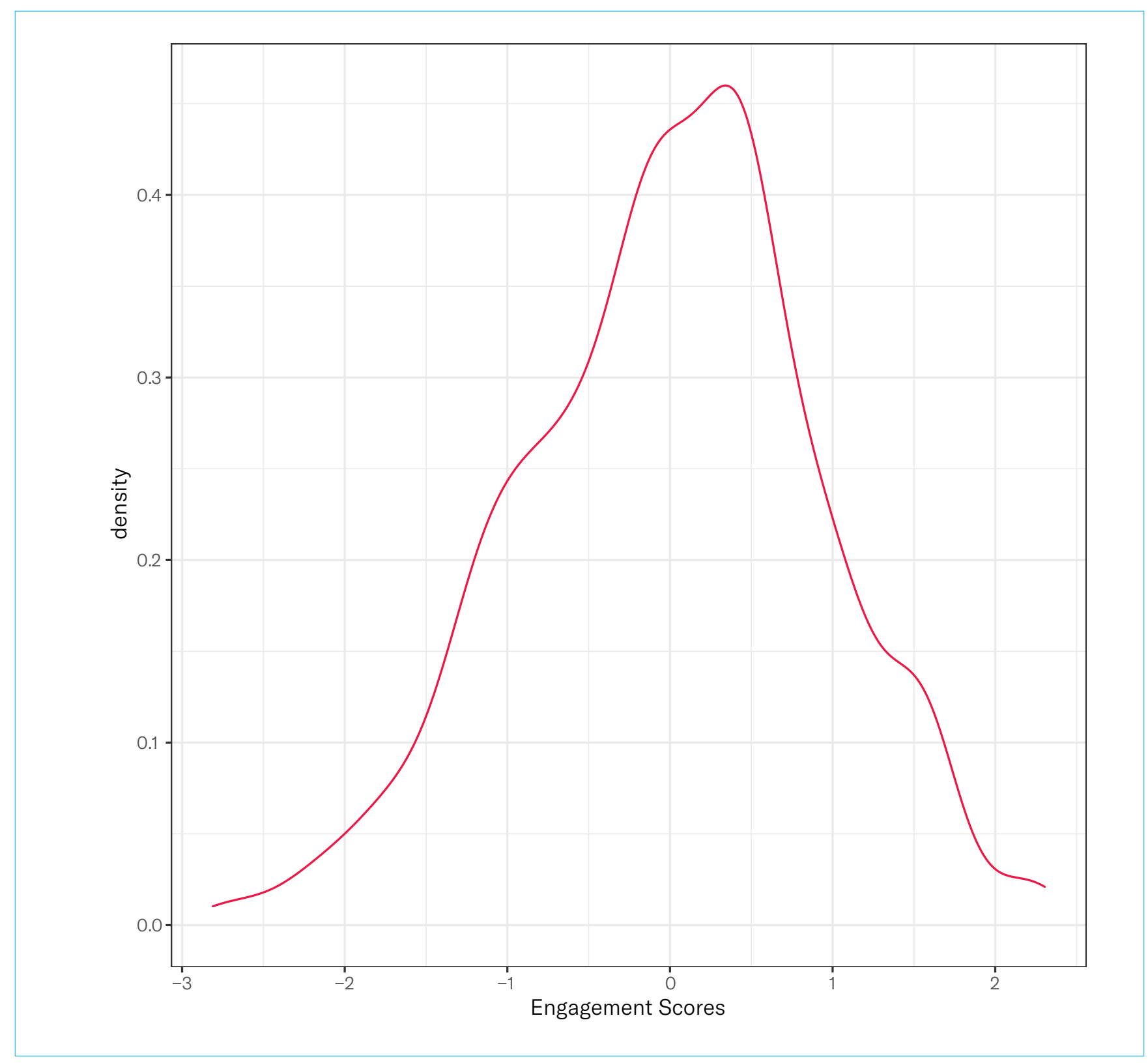

Figure 12. Distribution of engagement scores for this study sample. 


\section{Analysis}

To examine the effects of the experimental manipulation, we conducted regression analyses on each of the outcome variables (Connectedness, Authenticity, and Engagement). We hypothesized that the effect of the condition on the outcome variable would be moderated by science curiosity, and this effect would be conditional on gender.
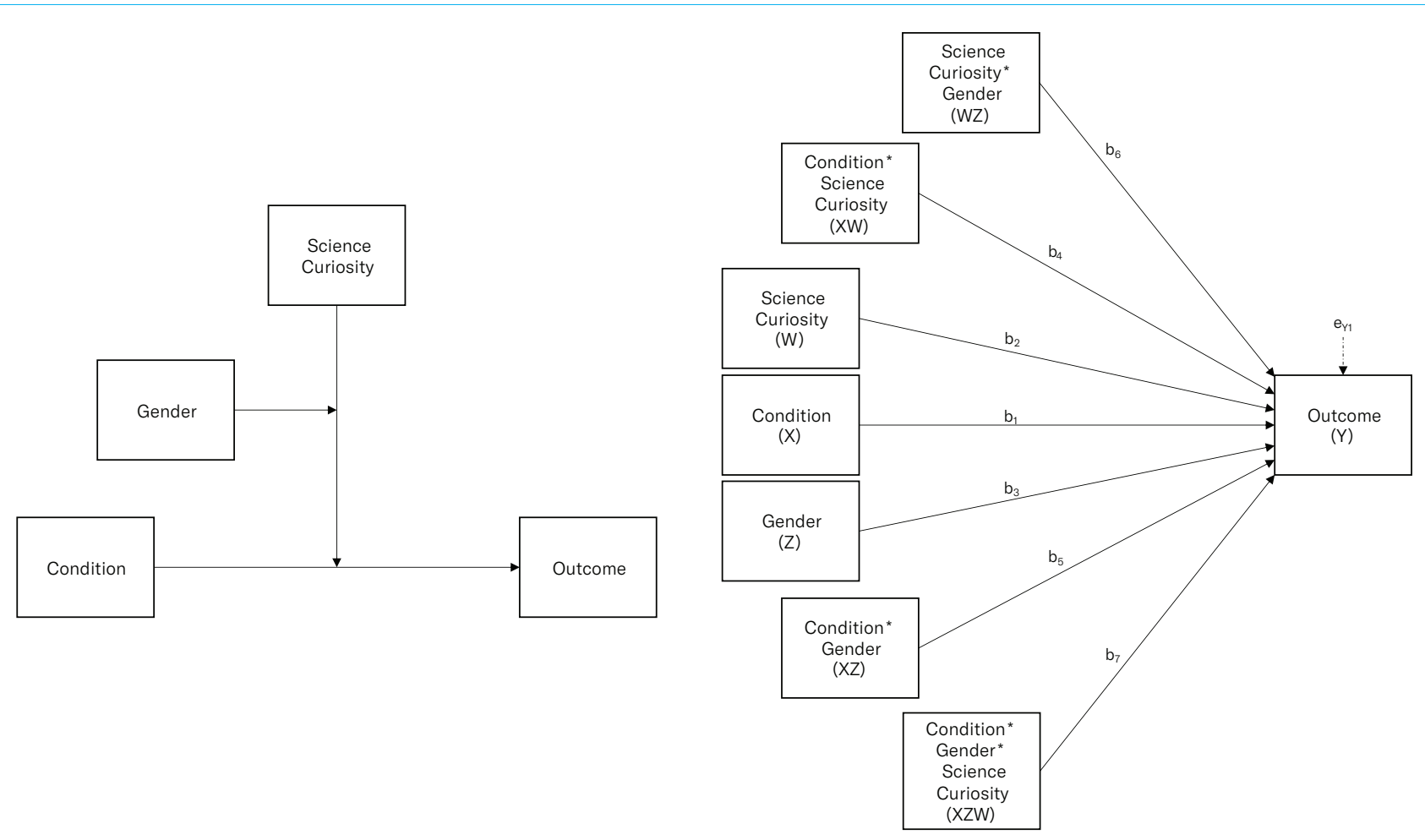

Figure 13. Conceptual (left) and statistical (right) diagrams.

\subsection{Predicting Connectedness}

Table 3. Model Summary - Predicting Connectedness

\begin{tabular}{|l|l|l|l|l|l|l|}
\hline $\mathrm{R}$ & $\mathrm{R}^{2}$ & $\mathrm{MSE}$ & $\mathrm{F}$ & $\mathrm{df}_{1}$ & $\mathrm{df}_{2}$ & $p$ \\
\hline .514 & .264 & .694 & 18.556 & 19 & 984 & $<.001$ \\
\hline
\end{tabular}

Table 4. Model - Predicting Connectedness

\begin{tabular}{|l|l|l|l|l|l|l|}
\hline \multicolumn{1}{|l|}{} & $b$ & se & $t$ & $p$ & LLCI & ULCI \\
\hline constant & -.037 & .069 & -.542 & .588 & -.173 & .098 \\
\hline BTS vs. original & & & & & & \\
\hline Stand-up (STA) & -.083 & .112 & -.748 & .455 & -.302 & .135 \\
\hline Pictures (PIC) & .040 & .107 & .373 & .709 & -.170 & .249 \\
\hline Produced (PRO) & .211 & .116 & 1.822 & .069 & -.016 & .437 \\
\hline Unproduced (UNP) & .052 & .109 & .474 & .635 & -.162 & .266 \\
\hline Science Curiosity (SCS) & .569 & .074 & 7.683 & $<.001$ & .424 & .714 \\
\hline STA X SCS & -.246 & .122 & -2.019 & .044 & -.486 & -.007 \\
\hline PIC X SCS & .024 & .122 & .193 & .847 & -.216 & .263 \\
\hline PRO X SCS & -.001 & .129 & -.005 & .996 & -.253 & .252 \\
\hline
\end{tabular}




\begin{tabular}{|c|c|c|c|c|c|c|}
\hline UNP X SCS & -.238 & .125 & -1.900 & .058 & -.484 & .008 \\
\hline Gender (GEND) & .056 & .101 & .551 & .582 & -.143 & .254 \\
\hline STA X GEND & .042 & .159 & .261 & .794 & -.271 & .354 \\
\hline PIC X GEND & -.003 & .156 & -.021 & .983 & -.310 & .303 \\
\hline PRO X GEND & -.297 & .167 & -1.781 & .075 & -.624 & .030 \\
\hline UNP X GEND & -.147 & .162 & -.906 & .365 & -.464 & .171 \\
\hline SCS X GEND & -.161 & .102 & -1.582 & .114 & -.360 & .039 \\
\hline STA X SCS X GEND & .276 & .162 & 1.705 & .089 & -.042 & .593 \\
\hline PIC X SCS X GEND & .120 & .166 & .724 & .469 & -.205 & .445 \\
\hline PRO X SCS X GEND & .228 & .176 & 1.293 & .196 & -.118 & .574 \\
\hline UNP X SCS X GEND & .500 & .174 & 2.878 & .004 & .159 & .841 \\
\hline
\end{tabular}

\subsection{Predicting Authenticity}

Table 5. Model Summary - Predicting Authenticity

\begin{tabular}{|l|l|l|l|l|l|l|}
\hline $\mathrm{R}$ & $\mathrm{R}^{2}$ & $\mathrm{MSE}$ & $\mathrm{f}$ & $\mathrm{df}_{1}$ & & \multicolumn{2}{c|}{} \\
\hline .348 & .121 & .672 & 7.133 & 19 & 984 & $<.001$ \\
\hline
\end{tabular}

Table 6. Model - Predicting Authenticity

\begin{tabular}{|c|c|c|c|c|c|c|}
\hline & $b$ & se & $t$ & $p$ & LLCI & ULCI \\
\hline constant & -.037 & .069 & -.542 & .588 & -.173 & .098 \\
\hline \multicolumn{7}{|l|}{ BTS vs. original } \\
\hline Stand-up (STA) & .011 & .110 & .103 & .918 & -.204 & .227 \\
\hline Pictures (PIC) & .195 & .105 & 1.856 & .064 & -.011 & .401 \\
\hline Produced (PRO) & .365 & .114 & 3.208 & .001 & .142 & .588 \\
\hline Unproduced (UNP) & .032 & .107 & .295 & .768 & -.179 & .242 \\
\hline $\begin{array}{l}\text { Science Curiosity } \\
\text { (SCS) }\end{array}$ & .311 & .073 & 4.267 & $<.001$ & .168 & .454 \\
\hline STA $\times$ SCS & -.218 & .120 & -1.815 & .070 & -.453 & .018 \\
\hline PIC X SCS & -.028 & .120 & -.232 & .816 & -.264 & .208 \\
\hline PRO X SCS & -.095 & .127 & -.752 & .452 & -.344 & .153 \\
\hline UNP X SCS & -.322 & .123 & -2.612 & .009 & -.564 & -.080 \\
\hline Gender (GEND) & .046 & .099 & .467 & .640 & -.148 & .241 \\
\hline STA X GEND & -.171 & .157 & -1.092 & .275 & -.478 & .136 \\
\hline PIC X GEND & -.264 & .154 & -1.719 & .086 & -.565 & .037 \\
\hline PRO X GEND & -.477 & .164 & -2.912 & .004 & -.799 & -.156 \\
\hline UNP X GEND & -.049 & .159 & -.308 & .758 & -.362 & .264 \\
\hline SCS X GEND & -.071 & .100 & -.711 & .477 & -.267 & .125 \\
\hline STA X SCS X GEND & .257 & .159 & 1.614 & .107 & -.055 & .569 \\
\hline PIC X SCS X GEND & .103 & .163 & .633 & .527 & -.217 & .423 \\
\hline PRO X SCS X GEND & .315 & .173 & 1.817 & .069 & -.025 & .655 \\
\hline UNP X SCS X GEND & .551 & .171 & 3.222 & .001 & .215 & .886 \\
\hline
\end{tabular}

Table 7. Test of higher order unconditional interaction - Predicting Authenticity

\begin{tabular}{|l|l|l|l|l|l|}
\hline & $\mathrm{R}^{2}$ Change & $\mathrm{F}$ & $\mathrm{df}_{1}$ & $\mathrm{df}_{2}$ & $p$ \\
Condition X SCS X GEND & .011 & 2.957 & 4 & 984 & .019
\end{tabular}


Table 8. Test of Condition by Science Curiosity interaction for each Gender

\begin{tabular}{|l|l|l|l|l|}
\hline & $\mathrm{F}$ & $\mathrm{df}_{1}$ & $\mathrm{df}_{2}$ & $p$ \\
\hline Females & 2.214 & 4 & 984 & .066 \\
\hline Males & 1.508 & 4 & 984 & .198 \\
\hline
\end{tabular}

\subsection{Predicting Engagement}

Table 9. Model Summary - Predicting Engagement

\begin{tabular}{|l|l|l|l|l|l|l|}
\hline $\mathrm{R}$ & $\mathrm{R}^{2}$ & $\mathrm{MSE}$ & $\mathrm{F}$ & $\mathrm{df}_{1}$ & $\mathrm{df}_{2}$ & $p$ \\
\hline .408 & .167 & .713 & 10.357 & 19 & 984 & $<.001$ \\
\hline
\end{tabular}

Table 10. Model - Predicting Engagement

\begin{tabular}{|c|c|c|c|c|c|c|}
\hline & $b$ & se & $t$ & $p$ & LLCI & ULCI \\
\hline constant & .085 & .070 & 1.218 & .224 & -.052 & .223 \\
\hline \multicolumn{7}{|l|}{ BTS vs. original } \\
\hline Stand-up (STA) & -.060 & .113 & -.533 & .594 & -.282 & .162 \\
\hline Slideshow (PIC) & .155 & .108 & 1.434 & .152 & -.057 & .368 \\
\hline Produced (PRO) & .171 & .117 & 1.461 & .144 & -.059 & .401 \\
\hline Unproduced (UNP) & -.067 & .111 & -.607 & .544 & -.284 & .150 \\
\hline $\begin{array}{l}\text { Science Curiosity } \\
\text { (SCS) }\end{array}$ & .456 & .075 & 6.079 & $<.001$ & .309 & .604 \\
\hline STA $\times$ SCS & -.286 & .124 & -2.316 & .021 & -.529 & -.044 \\
\hline PIC X SCS & -.124 & .124 & -.998 & .318 & -.366 & .119 \\
\hline PRO $\times$ SCS & -.310 & .130 & -2.377 & .018 & -.566 & -.054 \\
\hline UNP $\times$ SCS & -.339 & .127 & -2.669 & .008 & -.589 & -.090 \\
\hline Gender (GEND) & -.266 & .102 & -2.595 & .010 & -.466 & -.065 \\
\hline STA X GEND & .038 & .161 & .233 & .815 & -.279 & .354 \\
\hline PIC X GEND & -.069 & .158 & -.435 & .664 & -.379 & .242 \\
\hline PRO X GEND & -.187 & .169 & -1.110 & .267 & -.519 & .144 \\
\hline UNP X GEND & .198 & .164 & 1.206 & .228 & -.124 & .520 \\
\hline SCS X GEND & -.118 & .103 & -1.149 & .251 & -.320 & .084 \\
\hline STA X SCS X GEND & .266 & .164 & 1.620 & .106 & -.056 & .588 \\
\hline PIC X SCS X GEND & .373 & .168 & 2.224 & .026 & .044 & .703 \\
\hline PRO X SCS X GEND & .333 & .179 & 1.865 & .062 & -.017 & .684 \\
\hline UNP X SCS X GEND & .488 & .176 & 2.770 & .006 & .142 & .834 \\
\hline
\end{tabular}




\section{STUDY INSTRUMENT}

\section{S_AGE}

Please share your thoughts and views in our research project!

\section{What is this project studying?}

Our study is part of a collaboration between media professionals and researchers at Texas Tech University. This study will help us learn more about how people engage with different types of media. What we learn may help people, and we hope to publish this study widely to make it as beneficial as possible.

\section{What would I do if I participate?}

In this study, you will be asked some questions about your views and preferences. At the end, we will ask you some standard demographic questions.

\section{Can I quit if I become uncomfortable?}

Yes, absolutely. Your participation is completely voluntary. Dr. Landrum and the Institutional Review Board have reviewed the questions and think you can answer them comfortably. You may skip any question you do not feel comfortable answering by choosing the "I prefer not to answer" option. You can also stop answering questions at any time. You are free to close the survey any time you wish. Participating is your choice. However, we do appreciate any help you are able to provide.

\section{How long will participation take?}

We are asking for 15 to 25 minutes of your time. Most people will finish in about 20 minutes.

\section{How are you protecting privacy?}

The questionnaires will not request any personal identifying information to protect your privacy. Even though the surveys are anonymous, we ask that you answer as honestly as possible because we really want to learn more about how people think, and that requires our participants to provide honest answers.

\section{How will I benefit from participating?}

Besides providing the project with valuable information you will be compensated the amount you agreed upon before you entered into the survey.

\section{I have questions about this study. Who can I ask?}

The study is being conducted by Dr. Landrum from the College of Media and Communication at Texas Tech University. If you have questions about the study, you can email her at a.landrum@ttu.edu. TTU also has a Board that protects the rights of people who participate in research. You can call to ask them questions at 806-742-2064. You can email your questions to the Human Research Protection Program at hrpp@ttu.edu or mail questions to the Human Research Protection Program, Office of the Vice President for Research, Texas Tech University, Lubbock, Texas 79409.

To participate in our study, you must be 18 years old or older and live in the United States.

Are you....

Under 18

18 or Older

S_US Do you live in the United States of America?

Yes (1)

No (2) 
AGE How old are you? (in years)

GEND Which best reflects your gender?

1. Male

2. Female

3. Diverse (e.g., trans, nonbinary, etc; please specify)

9. I choose to not answer

RACE Which best describes your race/ethnicity? Please check all that apply.

1. White/ Caucasian

2. Black or African American

3. Hispanic or Latino

4. Asian/ Asian-American

5. Native American/ Alaska Native

6. Native Hawaiian/ Pacific Islander

7. Other (please specify)

9. I choose not to answer

End of Block: CONSENT

Start of Block: SCS Scale

\section{News Interest}

There are a lot of issues in the news and it is hard to keep up with every area. We will list some topics that get covered in the media. Please indicate how closely you follow the news relating to each topic either in the newspaper, on television, on radio, or on the internet. [1. Not at all; 2. A little but not closely; 3. Closely but not very closely; 4. Very closely.]

[randomize, separate page]

1. NI_CRIME. Crime

2. NI EDUC. Education

3. NI_GOV. Government or politics

4. NISSPORT. Sports

5. NI_RELIG. Religion

6. NI_INT. International affairs

7. NI_BUS. Business or finance

8. NI_SCI. Scientific research or discoveries

9. NI_TECH. New technologies

10. NI_ENT. Entertainment or celebrities

11. NI_WEA. Local weather

12. NI_HAW. Health and wellness

13. NI_WILDLIFE. Nature or Wildlife 


\section{Leisure Activity}

We'd also like to know about some of the activities you engage in. We will list some activities. Please indicate how many times you engaged in the activity in the last year.

[randomize except PUBLICLECTUREb. immediately after PUB LECTUREa; separate page; ]

1. LA_SCI. visited a science or technology museum

2. LA_SPORT. attended a live sports event

3. LA_ART. visited an art museum

4. LA_MUS. attended a musical performance or concert

5. LA_ZOO. went to a zoo or aquarium

6. LA_LIB. went to a public library

7. LA_GUN. went to a gun show

8. LA_PARK. visited a theme park or amusement park

9. LA_POLI. participated in a political rally or attended a political event

10. LAHUNT. went hunting or fishing

11. LAHIKE. went hiking

12. LAPUB LECTUREa. attended a public lecture

\section{Books}

We'd also like to know whether you read books in your spare time. We will list some book topics. Please indicate whether you have read a book on that topic in the previous year.

[randomize, separate page]

1. B_CRIME. Real life crime

2. B_SCIFI. Science fiction

3. B_MYST. A mystery novel

4. B_ED. Education

5. B_POLGOV. Government or politics

6. B_SPORT. Sports

7. B_RELIG. Religion (other than holy scripture text)

8. B_INTL. International affairs

9. B_BUS. Business or finance

10. B_SCI. Scientific research or discoveries

11. B_HIST. History or historical fiction

12. B_HAW. Health and wellness

13. B_WILDLIFE. Nature or wildlife 


\section{Conversation}

We are also interested in knowing about the sorts of topics you discuss with family members, friends, or co-workers. We will list some conversation topics. Please indicate about how often you discuss these topics with either friends, family members, or co-workers. [Never; rarely; more than rarely but not often; often]

[randomize, separate page]

1. C_CRIME. Crime

2. C_EDUC. Education

3. C_GOV. Government or politics

4. C_SPORT. Sports

5. C_RELIG. Religion

6. C_INTL. International affairs

7. C_BUS. Business or finance

8. C_SCI. Scientific research or discoveries

9. C_TECH. New technologies

10. C_ENT. Entertainment or celebrities

11. C_HAW. Health and wellness

12. C_WILDLIFE. Nature or wildlife

\section{Social media}

We would also like to know the kinds of videos, articles, and posts you share and how often you share them. Please indicate how often you share each of the following: [1. Never; 2. A few times a year at most; 3. A few times a month; 4. At least once a week; 5. EVERY day [randomize items on left]

1. sm_WOR. World events

2. sm_SPO. Sports

3. sm_GOV. Government or politics

4. sm_RELIG. Religion

5. sm_BUS. Business or finance

6. sm_SCI.Scientific research or discoveries

7. sm_TECH. New technologies

8. smENTERTAIN. Entertainment or celebrities

9. NI_HAW. Health and wellness

10. NI_WILDLIFE. Nature or Wildlife 


\section{Interests}

We will now list some topics that some people are interested in, and some people are not interested in. For each topic, please indicate how interested you are in that topic. [1 Not at all interested; 2 slightly interested; 3 moderately interested; 4 very interested]

1. I_GOV. Government or politics

2. I_SPORT. Sports

3. I_RELIG. Religion

4. I_TRAV. Foreign/International travel

5. I_SCI. Scientific research or discoveries

6. I_BUS. Business or Finance

7. I_ENT. Entertainment or celebrities

8. I_WILDLIFE. Nature or Wildlife

9. I_MUS. Music

10. I_HAW. Health and wellness

\section{Reading Selection}

Now we'd like to get your reactions to an interesting news story. One story will be drawn randomly from the story set of your choice. After you read the story, we'll ask you some questions about it. Please pick the story set that contains the stories you'd be most interested in reading.

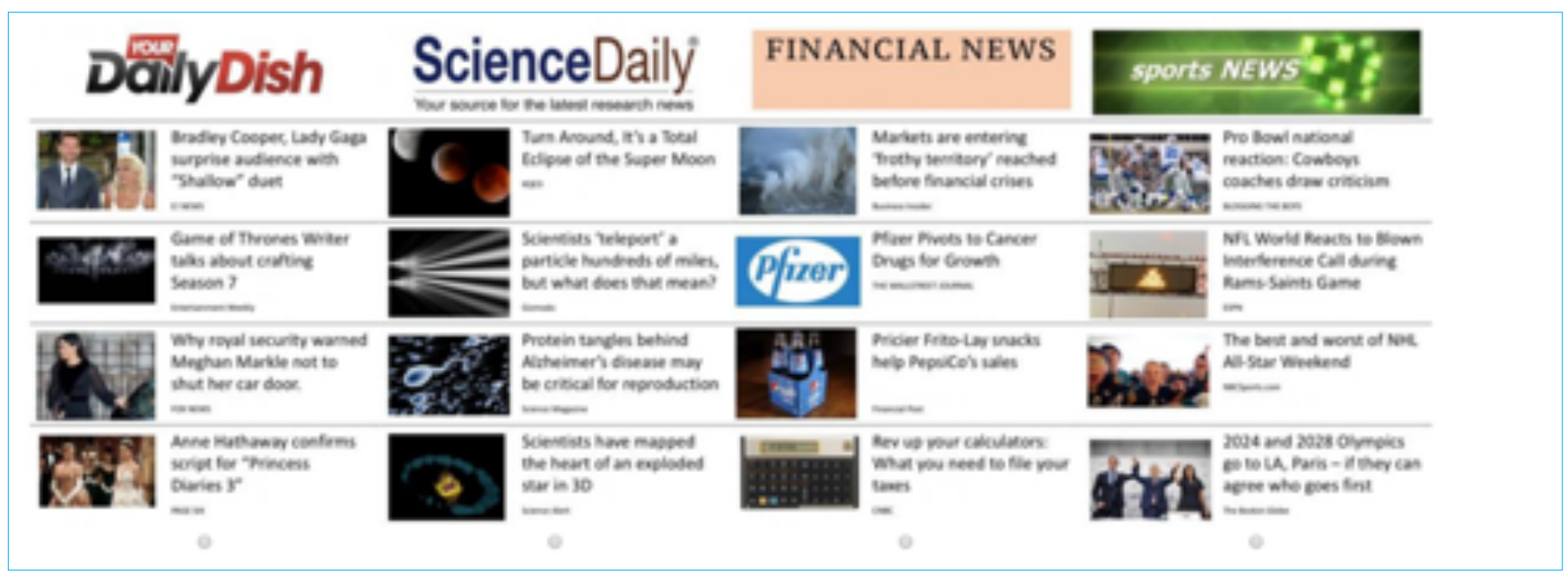




\section{SEL_ENT}

\section{Why royal security warned Meghan Markle not to shut her car door}

Meghan Markle was celebrated for closing her own car door in September just like the plebeians, but royal security officers are against it for a serious practical reason: The Duchess of Sussex's safety.

A new report claims that Markle, 37, has been warned by police not to close her car door behind her in case of an attack after she and Prince Harry allegedly faced threats from the far-right - because vehicles royals travel in have self-locking doors.

"Meghan and Harry like to meet the public as much as possible and make contact with the crowds that come to see them. And although having a car door closed might seem like a trivial thing, it could be the difference [in life or death]," a source told The Sun on Sunday.

"God forbid if anything did go wrong arriving at a royal engagement, but security need to be able to get them back into cars in seconds if needs be. If they're closed and locked, it's impossible."

A former royal protection officer also revealed to Hello! magazine why Markle and fellow duchess Kate Middleton are often seen without seatbelts: It's usually to avoid wrinkling their clothes.

He added, "Sometimes royals aren't strapped in for their own safety, for example, if they might need to make a quick escape in an emergency."

A rep for Kensington Palace did not immediately return Fox News' request for comment on royal protocol.

\section{If you saw this article on social media, which of the following would have been your reaction?}

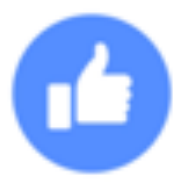

Like

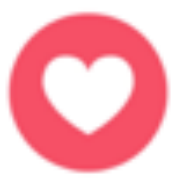

Love

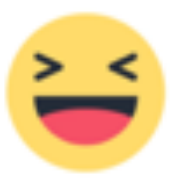

Haha

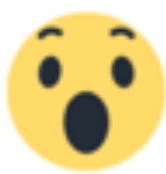

Wow

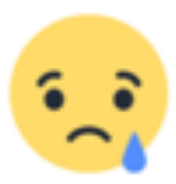

Sad

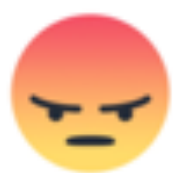

Angry

SEL_BUS

\section{Pricier Frito-Lay snacks help boost PepsiCo's sales}

NEW YORK - PepsiCo said pricier snacks and drinks boosted its sales in North America during the second quarter, even though the amount of products it sold in the region didn't change from a year ago.

Sales in the Frito-Lay snacks division rose 3.5 percent in North America, with PepsiCo Chief Financial Officer Hugh Johnston attributing the increase to price hikes as well as more "premium" products like Lay's Poppables, which are puffed up pieces of potato.

PepsiCo, like other major packaged food makers, is working on cutting costs and transforming its product lineup to reflect shifting tastes. In the saturated North American market, it's also trying to push up revenue with pricier products since increasing sales volume can be difficult.

For PepsiCo, the push has included the introduction of a pricier bottled water that is intended to compete with Coca-Cola's Smartwater. The company said Tuesday that the drink, Lifewtr, is performing well. But volume in the company's North America beverages unit, which also includes Diet Pepsi, Gatorade and Aquafina, was flat as a result of declines in other brands. Revenue rose 1 percent.

The Purchase, New York-based company noted challenging economic conditions in many overseas regions where it does business, including in Latin America. 
For the quarter ended June 17, PepsiCo Inc.'s profit rose 5 percent to $\$ 2.11$ billion, or $\$ 1.46$ per share. Earnings excluding non-recurring costs were $\$ 1.50$ per share. That topped Wall Street projections by 11 cents, according to a survey by Zacks Investment Research.

Total revenue rose 2 percent to $\$ 15.71$ billion, also edging out analyst expectations.

PepsiCo expects earnings of $\$ 5.13$ per share for the year, a penny shy of Wall Street expectations, according to FactSet.

Shares of PepsiCo Inc. fell 97 cents to $\$ 113.30$ in morning trading.

If you saw this article on social media, which of the following would have been your reaction?

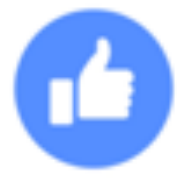

Like

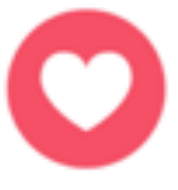

Love

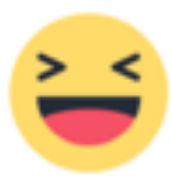

Haha

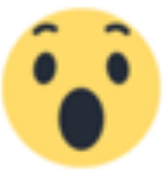

Wow

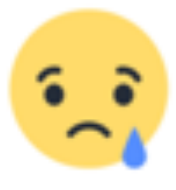

Sad

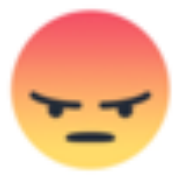

Angry

SEL_SPO

Olympics in 2024 \& 2028: Paris \& Los Angeles get Games as IOC backs dual host announcement

Paris and Los Angeles are set to stage the 2024 and 2028 Olympic Games - provided they can agree which should go first, as both want to host in 2024.

The International Olympic Committee has voted in favour of naming hosts for successive Games on 13 September with just Paris and Los Angeles bidding.

The IOC - which oversees the Olympic movement - wants the cities to reach an agreement on who hosts in 2028 by then.

If there is no agreement, a vote to select just the 2024 host will be held.

Budapest, Hamburg and Rome withdrew from the race for the 2024 event.

IOC president Thomas Bach told reporters after the meeting he hoped the agreement would be reached next month.

And LA organisers said they were "thrilled" with the decision, adding: "We look forward to working with the $I O C$ and Paris in the weeks ahead to turn this golden opportunity into a golden future together."

In June, Los Angeles bid chair Casey Wasserman appeared to concede to Paris when he said: "We have never been only about 2024."

However, a spokesman later told BBC Sport: "LA is the ideal host city for 2024 and is not conceding anything in the race for the 2024 Games.

Paris has said it has to go first as the site it has earmarked for the Olympic Village will not be available for redevelopment after 2024.

If you saw this article on social media, which of the following would have been your reaction?

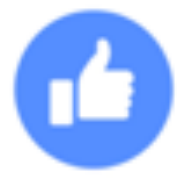

Like

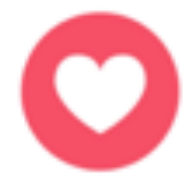

Love

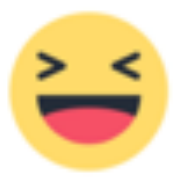

Haha

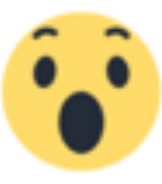

Wow

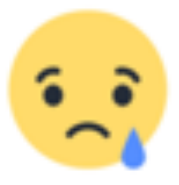

Sad

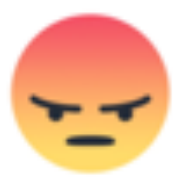

Angry 


\section{SEL_SCI}

\section{Turn Around, It's a Total Eclipse of the Super Moon}

In the evening hours of Sunday, Jan. 20, a total lunar eclipse will transform a full moon into a three-hourplus celestial extravaganza. Not only will we witness the breathtaking beauty of the eclipse, but we'll watch it during a super moon, when the moon is near its closest approach to Earth and appears larger in our sky than at any other time.

The best part of the show, when the moon begins to enter Earth's full shadow (or umbra), begins at 7:33 p.m. and lasts until 10:50 p.m. Pacific Standard Time, when the moon will slip out of the shadow.

The moon will be fully engulfed in Earth's umbra starting at 8:41 p.m. This state of "totality" will last a full hour - so there's plenty of time to enjoy the show. During totality, the moon will be high and rising higher in the Eastern sky.

Chabot Space \& Science Center will be hosting a special eclipse-viewing event from 6 p.m. to 11:30 p.m., so come on up if you want to make this breathtaking spectacle of nature a memorable social event. (The forecast is for rain showers during the day on Sunday, becoming partly cloudy by evening. Keep your fingers crossed!)

\section{What You Will See}

A total lunar eclipse is sometimes referred to as a "blood moon" for the reddish hues it acquires during totality. The color can range from coppery to orange to downright red, depending on atmospheric conditions and the moon's position in the sky.

The reddish color is an effect of Earth's atmosphere, which filters out the bluer tones of sunlight and lets the redder colors pass through unhindered--like red stained-glass. That reddened, filtered sunlight grazing the edge of the Earth passes on and is bent into Earth's shadow.

This filtering of sunlight by the atmosphere is the same effect that makes the sun appear orange or red at sunrise or sunset.

Without these effects of Earth's atmosphere, the moon would go almost completely dark upon entering the umbra. Instead, the light from all of Earth's sunrises and sunsets softly illuminate the eclipsed moon, producing a celestial night light in the sky.

You may find that the eclipsed moon looks more like a three-dimensional ball, rather than the flattish disk the full moon usually appears as. This quality is mostly due to the darkened moon not being overwhelmingly bright, as a full moon tends to be. The ruddy coloration may also have something to do with this, accentuating the moon against the otherwise black-and-white night sky.

\section{If you saw this article on social media, which of the following would have been your reaction?}

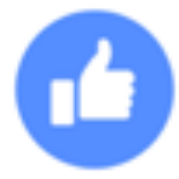

Like

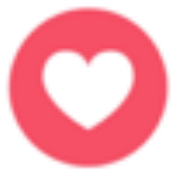

Love

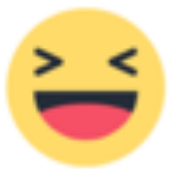

Haha

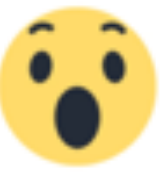

Wow

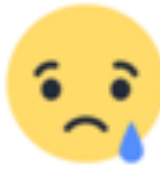

Sad

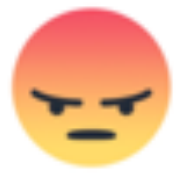

Angry

End of Block: SCS Selection

Start of Block: Treatment: Crabs and UBTS 


\section{Crab_UBTS}

As you know, companies and individuals produce video content on a wide variety of topics for people with a wide variety of interests. We will now select a short story for you to watch, then we will ask you some questions about the video.

Press play to start the video.

Please select to continue (1)

Start of Block: Treatment: Crabs and UBTS

Crab_Pic As you know, companies and individuals produce video content on a wide variety of topics for people with a wide variety of interests. We will now select a short story for you to watch, then we will ask you some questions about the video.

Press play to start the video.

Please select to continue (1)

Start of Block: Treatment: Crabs and BTS

Crab_BTS As you know, companies and individuals produce video content on a wide variety of topics for people with a wide variety of interests. We will now select a short story for you to watch, then we will ask you some questions about the video.

Press play to start the video.

Please select to continue (1)

Start of Block: Treatment: Crabs

Crab As you know, companies and individuals produce video content on a wide variety of topics for people with a wide variety of interests. We will now select a short story for you to watch, then we will ask you some questions about the video.

Press play to start the video.

Please select to continue (1)

Start of Block: Treatment: Standup and Crabs

Crab_Lrn As you know, companies and individuals produce video content on a wide variety of topics for people with a wide variety of interests. We will now select a short story for you to watch, then we will ask you some questions about the video.

Press play to start the video.

Please select to continue (1)

Start of Block: Treatment: Sand Dollars and UBTS 
Sand_UBTS As you know, companies and individuals produce video content on a wide variety of topics for people with a wide variety of interests. We will now select a short story for you to watch, then we will ask you some questions about the video.

Press play to start the video.

Please select to continue (1)

Start of Block: Treatment: Sand Dollars and UBTS

Sand_BTS As you know, companies and individuals produce video content on a wide variety of topics for people with a wide variety of interests. We will now select a short story for you to watch, then we will ask you some questions about the video.

Press play to start the video.

Please select to continue (1)

Start of Block: Treatment: Sand Dollars and BTS Photos

Sand_Pic As you know, companies and individuals produce video content on a wide variety of topics for people with a wide variety of interests. We will now select a short story for you to watch, then we will ask you some questions about the video.

Press play to start the video.

Please select to continue (1)

Start of Block: Treatment: Sand Dollars

Sand. As you know, companies and individuals produce video content on a wide variety of topics for people with a wide variety of interests. We will now select a short story for you to watch, then we will ask you some questions about the video.

Press play to start the video.

Please select to continue (1)

Start of Block: Treatment: Standup and Sand Dollars

Sand_Lrn. As you know, companies and individuals produce video content on a wide variety of topics for people with a wide variety of interests. We will now select a short story for you to watch, then we will ask you some questions about the video.

Press play to start the video.

Please select to continue (1) 
Start of Block: Connectedness

Please indicate the extent to which you agree with the following statements. [1. Strongly disagree;

2. Disagree; 3. Somewhat disagree; 4. Somewhat agree; 5. Agree; 6. Strongly agree]

Watching the Deep Look video was an escape for me.

Watching the Deep Look video helped me to forget about the day's problems.

If I were in a bad mood, watching the Deep Look video would put me in a better mood.

I would love to be a narrator or production crew member on Deep Look.

I would love to join the production crew members while they film an episode of Deep Look.

I would love to meet the narrator and/or production crew members featured on Deep Look.

I imagine that the narrator and/or production crew members of Deep Look are friendly and likable.

I feel like I could be friends with the narrator and/or production crew members of Deep Look.

I would like to have memorabilia that relate to Deep Look (stickers, t-shirt, pictures, etc.).

I would read articles on the web related to Deep Look.

End of Block: Connectedness

Start of Block: Subjective Engagement

Interest Overall, how interesting did you find the Deep Look video?

Not at all interesting (1)

Only slightly interesting (2)

Between slightly interesting and moderately interesting (3)

Moderately interesting (4)

Between moderately interesting and very interesting (5)

Very interesting (6)

Inform Overall, how informative did you find the Deep Look video?

Not at all informative (1)

Only slightly informative (2)

Between slightly informative and moderately informative (3)

Moderately informative (4)

Between moderately informative and very informative (5)

Very informative (6)

Surp Did you find the information in the Deep Look video surprising?

Not at all surprising (1)

Only slightly surprising (2)

Between slightly surprising and moderately surprising (3)

Moderately surprising (4)

Between moderately surprising and very surprising (5)

Very surprising (6)

Check If you are reading this choose somewhat agree

Strongly disagree (2)

Somewhat disagree (3)

Neither agree nor disagree (4)

Somewhat agree (1)

Strongly agree (5) 
Atten Overall, how closely did you pay attention to the Deep Look video?

Not at all (1)

A little but not closely (2)

Closely but not very closely (3)

Very closely (4)

AQ1 Are there any questions you have about the information discussed in the video?

Yes (1)

No (2)

End of Block: Subjective Engagement

Start of Block: Deep Look Questions

AQ2 Like what? Please list as few or as many questions you'd like (up to 10).

AQ3 How likely are you to try to find out the answers to any question or questions you had about the information in the video story?

No likelihood at all (1)

Very small likelihood (2)

Small likelihood (3)

Modest likelihood (4)

High likelihood (5)

Very high likelihood (6)

End of Block: Deep Look Questions

Start of Block: Behavioral Engagement

Share Would you be interested in sharing the video that you just watched or other stories in the Deep Look series with friends and family? If you answer YES to this question, we will provide you with an internet link that you can share after completing the survey.

Yes (1)

No (2)

Email The producers of the story create and distribute videos like it on a regular basis. Would you be interested in receiving email updates when new stories in the Deep Look series are available? If you answer YES to this question, we will provide Deep Look with your e-mail address. But be assured that your personal contact information and your responses to the rest of this survey are kept strictly confidential.

Yes (Please provide the email you wish to use) (1)

No (2)

Update Deep Look also posts updates on Facebook, Twitter, Instagram, and other social media platforms. Would you be interested in receiving such updates? If you answer YES to this question, we will provide you with links you can use to subscribe to these updates after completing this survey.

Yes (1)

No (2)

Links Additionally, Deep Look posts links to new videos on its YouTube page. Would you be interested in receiving such updates? If you answer YES to this question, we will provide you with a link you can use to subscribe to these updates after completing this survey.

Yes (1)

No (2) 
Comment As you know, producers of video content on the internet often give viewers an opportunity to comment on such stories. Some viewers comment, others don't. The comments are often read by other people who have viewed or are thinking of viewing the story. We would like to know what comments, if any, you might make about the story you just watched. Please type any comments you have about this video in the text boxes below.

Comment 1

Comment 2

Comment 3

Comment 4

Comment 5

End of Block: Behavioral Engagement

Start of Block: Previous Exposure

Watch To the best of your knowledge, have you ever watched a video created by Deep Look in the past?

Yes (1)

No (2)

Watch_Cert How certain are you that you have watched a video created by Deep Look in the past?

Very certain (1)

Just somewhat certain (2)

Not very certain (3)

Subsc To the best of your knowledge, do you already subscribe to e-mails, social media, or other updates from Deep Look?

Yes (1)

No (2)

Sub_Cert How certain are you that you already subscribe to e-mails, social media, or other updates from Deep Look?

Very certain (1)

Just somewhat certain (2)

Not very certain (3)

End of Block: Previous Exposure

Start of Block: Authenticity

A_expect Based on the video that you just watched, we would like your first impressions on the following items. Please indicate the extent to which you agree with the following statements about the Deep Look series [1. Strongly disagree; 2. Disagree; 3. Somewhat disagree; 4. Somewhat agree; 5. Agree; 6. Strongly agree]:

Any Deep Look episode would meet my expectations.

I feel confident in the quality of Deep Look.

Deep Look would never disappoint me.

Deep Look guarantees satisfaction.

I think Deep Look is trustworthy.

I think Deep Look is competent.

I think Deep Look is honest.

I have very little confidence in the quality of Deep Look. 
End of Block: Authenticity

Start of Block: YouTube Use

YTU You are almost done!

We are hoping that you will help us better understand people's interests and uses of YouTube. How often do you use YouTube?

Never (1)

Only a few times a year at most (2)

At least once a month (3)

A few times a month (4)

At least once a week (5)

A few times a week (6)

At least daily (7)

YT_USES What would you say is the primary reason that you use YouTube?

to get information that interests me (1)

to look up something I don't know (2)

to listen to music (3)

to keep up with current issues and events (4)

to feel like I belong to a community (5)

to connect to people who share my values (6)

to relax or be entertained (7)

to pass the time when I'm bored (8)

End of Block: YouTube Use

Start of Block: Demographics

D_intro For the last part of this survey, we will ask you some basic demographic questions.

Q91 In which region do you currently reside?

Midwest (1)

Northeast (18)

West (19)

South (20)

EDUC What is the last grade you completed in school (or highest level of training completed)?

Grade 8 or lower (1)

Some high school, no diploma (2)

High school diploma, or equivalent (3)

Some college, no degree (4)

Associates, Technical college, or two-year college degree (5)

Bachelors or four-year college degree (6)

Graduate or professional school (7)

I choose not to answer (9) 
RGUID How much guidance does faith or religion provide in your day-to-day life?

A great deal (5)

A lot (4)

A moderate amount (3)

A little (2)

None at all (1)

I'm not religious (0)

I choose not to answer (9)

IDEO Generally speaking, would you describe your views as....

Very liberal (1)

Somewhat liberal (2)

Moderate (3)

Somewhat conservative (4)

Very conservative (5)

I choose not to answer (9)

PARTY When it comes to important political elections, whom do you tend to vote for?

The Democratic candidate (1)

The Republican candidate (2)

A third-party candidate (3)

I tend not to vote (4)

I choose not to answer (9)

INCOME Last year, what was the total income (before taxes) of all the people living in your household?

Less than 10,000 (1)

10,000 to less than 15,000 (2)

15,000 to less than 25,000 (3)

25,000 to less than 35,000 (4)

35,000 to less than 50,000 (5)

50,000 to less than 75,000 (6)

75,000 to less than 100,000 (7)

100,000 to less than 150,000 (8)

150,000 to less than 250,000 (9)

250,000 or more (10)

I choose not to answer (99)

End of Block: Demographics

Start of Block: Post-Interview Script

PIS Thank you for completing this survey! Below, please find the additional information you requested, based on the responses you gave to questions asked earlier in this survey: Here are links to Deep Look social media accounts:

Facebook: Facebook.com/deeplookpbs Twitter: Twitter.com/kqedscience Instagram: Instagram.com/ kqedscience

PIS_YT Here is a link to Deep Look's YouTube page:

https://www.youtube.com/user/KQEDDeepLook

End of Block: Post-Interview Script 